This PDF is a selection from a published volume from the National Bureau of Economic Research

Volume Title: Economic Regulation and Its Reform: What Have We Learned?

Volume Author/Editor: Nancy L. Rose, editor

Volume Publisher: University of Chicago Press

Volume ISBN: 0-226-13802-X (cloth); 978-0-226-13802-2 (cloth);

978-0-226-13816-9 (EISBN)

Volume URL: http://www.nber.org/books/rose05-1

Conference Date: September 9-10, 2005

Publication Date: June 2014

Chapter Title: Incentive Regulation in Theory and Practice:

Electricity Distribution and Transmission Networks

Chapter Author(s): Paul L. Joskow

Chapter URL: http://www.nber.org/chapters/c12566

Chapter pages in book: (p. 291 - 344) 


\title{
Incentive Regulation in Theory and Practice Electricity Distribution and Transmission Networks
}

\author{
Paul L. Joskow
}

\subsection{Introduction}

Over the last thirty years several network industries that evolved historically as either state-owned or private regulated vertically integrated monopolies have been privatized, restructured, and some vertical segments deregulated. These industries include telecommunications, natural gas, electric power, and railroads. The reform program typically involves the vertical separation (ownership or functional) of potentially competitive segments, which are gradually deregulated, from remaining network segments that are assumed to have natural monopoly characteristics and continue to be subject to price, network access, service quality, and entry regulations. In several countries, an important part of the reform agenda has included the introduction of "incentive regulation" mechanisms for the remaining regulated segments as an alternative to traditional "cost-of-service" or "rate-of-return" regulation. The expectation was that incentive regulation mechanisms would provide more powerful incentives for regulated firms to reduce costs, improve service quality in a cost effective way, stimulate (or at least not impede) the introduction of new products and services, and

Paul L. Joskow is president of the Alfred P. Sloan Foundation and is the Elizabeth and James Killian Professor of Economics Emeritus at the Massachusetts Institute of Technology.

I have benefited from extensive comments provided by David Sappington and from discussions with Jean Tirole, Richard O'Neil, and Michael Pollitt. I am grateful to Nancy Rose for helping me to finalize this version of the chapter and for contributing to it through our joint teaching at MIT. I thank the MIT Center for Energy and Environmental Policy Research and the Cambridge-MIT Institute for research support. While the original version of this chapter was being written in 2007 I was a director of National Grid plc (2000-2007) and TransCanada Corporation (2004-2013). I am presently a director of Exelon Corporation. For acknowledgments, sources of research support, and disclosure of the author's material financial relationships, if any, please see http://www.nber.org/chapters/c12566.ack. 
stimulate efficient investment in and pricing of access to regulated network infrastructure services.

Although much of the research on the "liberalization" of these sectors has focused on the evolution of the potentially competitive segments that have been deregulated (e.g., wholesale and retail electric power and natural gas markets), the performance of the remaining regulated network segments, and in particular the performance of new incentive regulation mechanisms, is also of considerable economic importance. These regulated segments often represent a significant fraction of the total price paid by consumers for retail service (prices for competitive plus regulated services). Moreover, the performance of the regulated segments can have important effects on the performance of the competitive segments when the regulated segments provide the infrastructure platform upon which the competitive segments rely (e.g., the electric transmission and distribution networks). Accordingly, the welfare consequences of these industry restructuring and deregulation initiatives depends on the performance of both the competitive and the regulated segments of these industries.

As the industry liberalization initiatives were gaining steam in Europe, Latin America, Australia, New Zealand, and North America during the late 1980s and the 1990s, theoretical research on the properties of alternative incentive regulation mechanisms developed quite rapidly as well. However, the relationship between theoretical developments and applications of incentive regulation theory in practice has not been examined extensively. In this chapter I provide an overview of the theoretical and conceptual foundations of incentive regulation theory, discuss some practical implementation issues, examine how incentive regulation mechanisms have been structured and applied to electric distribution and transmission networks (primarily in the United Kingdom where the application of these mechanisms is most advanced), review the limited available empirical analysis of the performance of incentive regulation mechanisms applied to electric distribution and transmission networks, and draw some conclusions about the relationships between incentive regulation theory and its application in practice.

As I will discuss, the implementation of incentive regulation concepts is more complex and more challenging than may first meet the eye. Even apparently simple mechanisms like price caps (e.g., so-called RPI-X regulation) are fairly complicated to implement in practice, are often imbedded in a more extensive portfolio of incentive regulation schemes, and depart in potentially important ways from the assumptions upon which related theoretical analyses have been based. Moreover, the sound implementation of incentive regulation mechanisms depends in part on information gathering, auditing, and accounting institutions that are commonly associated with traditional cost-of-service or rate-of-return regulation. These institutions are especially important for developing sound approaches to the treatment of capital expenditures, to develop benchmarks for operating costs, 
to implement resets ("ratchets") of prices, to take service quality attributes into account, and to deter gaming of incentive regulation mechanisms that have mechanisms for resetting prices or price adjustment formulas of one type or another over time.

\subsection{Theoretical and Conceptual Foundations}

\subsubsection{Overview}

The traditional textbook theories of optimal pricing for regulated firms characterized by subadditive costs and a budget constraint (e.g., marginal cost pricing, Ramsey-Boiteux pricing, nonlinear pricing, etc.) assume that regulators are completely informed about the technology, costs, and consumer demand attributes facing the firms they regulate and can somehow impose cost-minimization obligations on regulated firms (e.g., Boiteux 1960 [1951]; 1971 [1956]; Braeutigam 1989; Joskow 2007). ${ }^{1}$ The focus is then on second-best pricing given defined cost functions, demand attributes, and budget balance constraints, ${ }^{2}$ not on incentives to minimize costs or improve other dimensions of firm performance (e.g., service quality attributes).

Fully informed regulators clearly do not exist in reality. In reality, regulators have imperfect information about the cost and service quality opportunities and the attributes of the demand for services that the regulated firm faces. Moreover, the regulated firm generally has more information about these attributes than does the regulator or third parties, which have an interest in the outcome of regulatory decisions. Accordingly, the regulated firm may use its information advantage strategically in the regulatory process to increase its profits or to pursue other managerial goals, to the disadvantage of consumers (Owen and Braeutigam 1978; Laffont and Tirole 1993, chapter 1). These problems may be further exacerbated if the regulated firm can "capture" the regulatory agency and induce it to give more weight to its interests (Posner 1974; McCubbins 1985; Spiller 1990; Laffont and Tirole 1993, chapter 5). Alternatively, other interest groups may be able to "capture" the regulator and, in the presence of long-lived sunk investments, engage in "regulatory holdups" or expropriation of the regulated firm's assets. Higher levels of government, such as the courts and the legislature, also have imperfect information about both the regulator and the regulated firm and can monitor their behavior only imperfectly (McCubbins, Noll, and Weingast 1987).

1. This characterization is a little unfair since the development of much of this theoretical work was associated with economists in public enterprises who not only worked on optimal pricing but also developed methods for optimizing costs, reliability, and service quality in a public enterprise context.

2. In what follows I will use the terms "budget constraint," "firm viability constraint," and "firm participation constraint" interchangeably. 
The evolution of "traditional" regulatory practices in the United States actually has reflected efforts to mitigate the information disadvantages that regulators confront, as well as reflecting broader issues of regulatory capture and opportunities for monitoring by other levels of government, consumers, and other interest groups. These institutions and practices are reflected in: laws and regulations that require firms to adhere to a uniform system of capital and operating cost accounts; give regulators access to the books and records of regulated firms and the right to request additional information on a case by case basis; auditing requirements, staff resources to evaluate the associated information, transparency requirements such as public hearings and written decisions, ex parte communications rules; opportunities for third parties to participate in regulatory proceedings to (in theory) ${ }^{3}$ assist the regulatory agency in developing better information and reducing its regulatory disadvantage; and appeals court review and legislative oversight processes. In addition, since regulation is a repeated game, regulators (as well as legislators and appeals courts) can learn about the firm's attributes as they observe its responses to regulatory decisions over time and, as a result, the regulated firm naturally develops a reputation for the credibility of its claims and the information that it uses to support them.

However, although the development of US regulatory practice focused on improving the information available to regulators, the regulatory mechanisms adopted typically did not utilize this information nearly as effectively as they could have. While US regulatory practice differs significantly from the way it is often characterized, and during long periods of time provided incentives to control costs (Joskow 1974, 1989), formal incentive regulation mechanisms were historically used infrequently in the United States, Canada, Spain, Germany, and other countries with private rather than stateowned regulated network industries. Perhaps regulatory practice evolved this way due to the absence of a sound theoretical incentive regulation framework to apply in practice.

Beginning in the 1980s, theoretical research on incentive regulation rapidly evolved to confront directly imperfect and asymmetric information problems and related contracting constraints, regulatory credibility issues, dynamic considerations, regulatory capture, and other issues that regulators have been trying to respond to for decades but in the absence of a comprehensive theoretical framework to guide them. This theoretical framework is reasonably mature and can help regulators deal with these challenges much more directly and effectively (Laffont and Tirole 1993; Armstrong, Cowan, and Vickers 1994; Armstrong and Sappington 2004).

Consider the simplest characterization of the nature of the regulator's information disadvantages and its potential implications. A firm's cost opportunities may be high or low based on inherent attributes of its tech-

3. Of course, third parties may have an incentive to inject inaccurate information into the regulatory process as well. 
nical production opportunities, exogenous input cost variations over time and space, inherent differences in the costs of serving locations with different attributes (e.g., urban or rural), and so forth. While the regulator may not know the firm's true cost opportunities, she will typically have some information about their probability distribution. The regulator's imperfect information can be summarized by a probability distribution defined over a range of possible cost opportunities between some upper and lower bound within which the regulated firm's actual cost opportunities lie. Second, the firm's actual realized costs or expenditures will not only depend on its underlying cost opportunities but also on the behavioral decisions made by managers to exploit these cost opportunities. Managers may exert varying levels of effort to get more (or less) out of the cost opportunities that the firm has available to it. The greater the managerial effort the lower will be the firm's costs, other things equal. However, exerting more managerial effort imposes costs on managers and on society. Other things equal, managers will prefer to exert less effort than more to increase their own satisfaction, but less effort will lead to higher costs and more "x-inefficiency." Unfortunately, the regulator cannot observe managerial effort directly and may be uncertain about its quality and its impacts on actual costs.

The uncertainties the regulator faces about the firm's inherent cost opportunities and managerial effort gives the regulated firm a strategic advantage. The firm would like to convince the regulator that it is a "higher cost" firm than it actually is, in the belief that the regulator will then set higher prices for the services it provides as it satisfies the firm's long-run financial viability constraint (firm participation or budget-balance constraint), increasing the regulated firm's profits, creating deadweight losses from (second-best) prices that are too high, and allowing the firm to capture surplus from consumers. Thus, the social welfare maximizing regulator faces a potential adverse selection problem as it seeks to distinguish between firms with high cost opportunities and firms with low cost opportunities, while adhering to a firm budget balance constraint that must be satisfied whether the firm turns out to have either high or low cost opportunities.

The uncertainties that the regulator faces about the quantity and impact of managerial effort create another potential problem. Since the regulator typically has or can obtain good information about the regulated firm's actual costs (i.e., its actual expenditures), at least in the aggregate, one approach to dealing with the adverse selection problem outlined earlier would simply be to set (or reset after a year) prices to a level equal to the firm's ex post realized costs. This would solve the adverse selection problem since the regulator's information disadvantage would be resolved by auditing the firm's costs. ${ }^{4}$ This is the standard characterization of "cost-of-service" regulation.

4. Of course, the auditing of costs may not be perfect and in a multiproduct context the allocation of accounting costs between different products is likely to reflect some arbitrary joint cost allocation decisions. 
However, if the loss of the opportunity for the firm and its managers to earn rents reduces managerial effort and less managerial effort increases the firm's costs, this kind of "cost plus" regulation may lead management to exert too little effort to control costs, increasing the realized costs above their efficient levels. If the "rat doesn't smell the cheese and sometimes gets a bit of it to eat" he may play golf rather than working hard to achieve efficiencies for the regulated firm. Thus, the regulator faces a potential moral hazard problem associated with variations in managerial effort in response to regulatory incentives (Laffont and Tirole 1986; Baron and Besanko 1987b).

Faced with these information disadvantages, the social welfare maximizing regulator will seek a regulatory mechanism that takes both the social costs of adverse selection and moral hazard into account, subject to the firm participation or budget-balance constraint that it faces, balancing the costs associated with adverse selection and the costs associated with moral hazard. The regulator may also take actions that reduce her information disadvantages by, for example, increasing the quality of the information that the regulator has about the firm's cost opportunities.

Following Laffont and Tirole (1993, 10-19), to illuminate the issues at stake, we can think of two polar case regulatory mechanisms that might be applied to a monopoly firm producing a single product. The first regulatory mechanism involves setting a fixed price ex ante that the regulated firm will be permitted to charge going forward (i.e., effectively forever). Alternatively, we can think of this as a pricing formula that starts with a particular price and then adjusts this price for exogenous changes in input price indices and other exogenous indices of cost drivers (forever). This regulatory mechanism can be characterized as a fixed price regulatory contract or, in a dynamic setting, a price cap regulatory mechanism, where prices adjust based on exogenous input price and performance benchmarks. There are two important attributes of this type of regulatory mechanism. Because prices are fixed (or vary based only on exogenous indices of cost drivers) and do not respond to changes in managerial effort or ex post cost realization, the firm and its managers are the residual claimants on production cost reductions and the costs of increases in managerial effort (and vice versa). That is, the firm and its managers have the highest powered incentives fully to exploit their cost opportunities by exerting the optimal amount of effort (Brennan 1989; Cabral and Riordan 1989; Isaac 1991; Sibley 1989; Kwoka 1993). Accordingly, this mechanism provides optimal incentives for inducing managerial effort and eliminates the costs associated with managerial moral hazard. However, because the regulator must adhere to a firm participation or financial viability constraint, when there is uncertainty about the regulated firm's cost opportunities the regulator will have to set a relatively high fixed price (or dynamic price cap) to ensure that if the firm is indeed inherently high cost, the prices under the fixed price contract or price cap will be high enough to cover the firm's (efficient) realized costs. Accordingly, while a fixed price 
mechanism may deal well with the potential moral hazard problem by providing high-powered incentives for cost reduction, it is potentially very poor at "rent extraction" for the benefit of consumers and society, potentially leaving a lot of rent to the firm due to the regulator's uncertainties about the firm's inherent costs and its need to adhere to the firm viability or participation constraint. Thus, while a fixed price type incentive mechanism solves the moral hazard problem, it incurs the full costs of adverse selection.

At the other extreme, the regulator could implement a "cost-of-service" contract or regulatory mechanism where the firm is assured that it will be compensated for all of the costs of production that it actually incurs. Assume for now that this is a credible commitment - there is no ex post renegotiation - and that audits of the expenditures the firm has incurred are accurate. When the firm produces it will then reveal whether it is a high cost or a low cost firm to the regulator. Because the regulator compensates the firm for all of its costs, there is no "rent" left to the firm or its managers in the form of excess profits. This solves the adverse selection problem. However, this kind of cost-of-service recovery mechanism does not provide any incentives for the management to exert optimal (any) effort. If the firm's profitability is not sensitive to managerial effort, the managers will exert the minimum effort that they can get away with. Even though there are no "excess profits" left on the table since revenues are equal to the actual costs the firm incurs, consumers are now paying higher prices than they would have to pay if the firm were better managed and some rent were left with the firm and its managers. Indeed, it is this kind of managerial slack and associated $\mathrm{x}$-inefficiencies that most policymakers have in mind when they discuss the "inefficiencies" associated with regulated firms. Thus, while the adverse selection problem can be solved in this way, the costs associated with moral hazard are fully realized.

Accordingly, these two polar case regulatory mechanisms each have both positive and negative attributes. One is good at providing incentives for managerial efficiency and cost minimization, but it is bad at extracting the benefits of the lower costs for consumers. The other is good at rent extraction but leads to inefficiencies due to moral hazard resulting from suboptimal managerial effort. Perhaps not surprisingly, the optimal regulatory mechanism (in a second-best sense) will lie somewhere between these two extremes. In general, it will have the form of a profit sharing contract or a sliding scale regulatory mechanism, where the price that the regulated firm can charge is partially responsive to changes in realized costs and partially fixed ex ante (Schmalensee 1989b; Lyon 1996). More generally, by offering a menu of cost-contingent regulatory contracts with different cost-sharing provisions, the regulator can do even better than if it offers only a single profit-sharing contract (Laffont and Tirole 1993). The basic idea here is to make it profitable for a firm with low cost opportunities to choose a relatively high-powered incentive scheme and a firm with high cost opportunities a 
relatively low-powered scheme. Some managerial inefficiencies are incurred if the firm turns out to have high cost opportunities, but these costs are balanced by reducing the rent left to the firm if it turns out to have low cost opportunities.

Consider the following simple example that illustrates the value of offering a menu of regulatory contracts to the regulated firm. ${ }^{5}$ Assume that there are two options, a fixed price contract or a cost-of-service contract. By offering this menu the regulator can present a more demanding fixed priced contract because the cost-of-service contract ensures that the firm's budget constraint will not be violated. If the fixed price contract is too demanding the firm will choose the cost-of-service contract. However, if the firm is potentially a very low-cost supplier and chooses the fixed price contract, more rents will be conveyed to consumers.

We can capture the nature of the range of options in the following fashion. Consider a general formulation of a regulatory process in which the firm's allowed revenues, $R$, are determined based on a fixed component, $a$, and a second component that is contingent on the firm's realized costs, $C$, and where $b$ is the sharing parameter that defines the responsiveness of the firm's revenues to realized costs.

$$
R=a+(1-b) C .
$$

Under a fixed price contract or price cap regulation:

$$
\begin{aligned}
& a=C^{*}, \text { where } C^{*} \text { is the regulator's assessment of the "efficient" } \\
& \text { costs of the highest cost type and } \\
& b=1 .
\end{aligned}
$$

Under pure cost-of-service regulation where the regulator can observe the firm's expenditures but not evaluate their efficiency: ${ }^{6}$

$$
\begin{aligned}
& a=0 \\
& b=0 .
\end{aligned}
$$

Under profit-sharing contract or sliding scale regulation (performance based regulation, or PBR)

$$
\begin{aligned}
& 0<b<1 \\
& 0<a<C^{*} .
\end{aligned}
$$

The challenges then are to find the optimal performance based mechanism given the information structure faced by the regulator and for the regulator to find ways to reduce its information disadvantages vis-à-vis the regulated

5. I am grateful to David Sappington for providing this example.

6 . This is not a particularly accurate characterization of cost-of-service regulation in practice in the United States, but it has become the common characterization of it, especially among those who had no experience with it (Joskow and Schmalensee 1986). 
firm and to use the additional information effectively. Laffont-Tirole show that it is optimal for the regulator to offer a mеnu of contracts with different combinations of $a$ and $b$ that meet certain conditions driven by the firm's budget constraint and an incentive compatibility constraint that leads firms with low cost opportunities to choose a high-powered scheme ( $b$ is closer to 1 and $a$ is closer to the efficient cost level for a firm with low cost opportunities) and firms with high cost opportunities to choose a lower powered incentive scheme ( $a$ and $b$ are closer to zero). The lower powered scheme is offered to satisfy the firm participation constraint, sacrificing some costs resulting from managerial moral hazard, in order to reduce the rents that must be left to the low cost firm as it is induced to exert the optimal amount of managerial effort while satisfying the firm viability constraint if it turns out to be a high cost opportunity firm. (So far, this discussion has ignored quality issues. Clearly if a regulatory mechanism focuses only on reducing costs and ignores quality it will lead to firms providing too little quality. This is a classic problem with pure fixed price or price cap mechanisms and will be discussed further in the following.)

The incentive regulation literature is not a substitute for the older literature on optimal pricing for natural monopolies subject to a budget constraint, but rather a complement to it. This can be seen most clearly in the framework developed by Laffont and Tirole where the availability of government transfers creates a dichotomy or separation between optimal pricing and optimal incentives for controlling costs (Laffont and Tirole 1993, chapter 2). As a result, all of the basic second-best optimal pricing results for a natural monopoly subject to a budget constraint continue to be applied alongside the application of optimal incentive schemes (given asymmetric information) for controlling production costs. More generally, however, pricing and incentives cannot be so easily separated and their effects are likely to be interdependent. Some mechanisms can provide both good pricing and performance (cost, quality) incentives, but typically, the desire to get prices as well as performance incentives right creates another constraint that moves us further from first-best outcomes. Legal, political, bureaucratic, and other constraints may also be quite important in practice.

\subsubsection{Incentive Regulation Theory Typology}

The many papers that have contributed to the development of incentive regulation theory reflect a wide range of assumptions about the nature of the information possessed by the regulator and the firm about costs, costreducing managerial effort, demand and product quality, the attributes of the regulatory instruments available to the regulator, the risk preferences of the firm, regulatory capture by interest groups, regulatory commitment, flexibility, and other dynamic considerations. These alternative sets of assumption can be applied in both a single or multiproduct context. One strand of the literature initially focused primarily on adverse selection problems 
motivated by the assumption that regulators could not observe a firm's costs and ignoring the role of managerial effort (Baron and Meyerson 1982; Lewis and Sappington 1988a, 1988b). Another strand of the literature focused on both adverse selection and moral hazard problems motivated by the assumption that regulators could observe a firm's realized cost ex post, had information about the probability distribution of a firm's cost ex ante, and that managerial effort did affect costs but that this effort was not observable by the regulator (Laffont and Tirole 1986). Over time, these approaches have evolved to cover a similar range of assumptions about these basic information and behavioral conditions and lead to qualitatively similar conclusions. Armstrong and Sappington (2007) provide a comprehensive and thoughtful review and synthesis of this entire literature and I refer readers interested in a very detailed treatment of the full range of specifications of incentive regulation problems to their paper. Here I will simply lay out a "typology" of how these issues have been developed in the literature.

What are the regulator's objectives? Much of the literature assumes that the regulator seeks to maximize a social welfare function that reflects the goal of limiting the rents that are transferred from consumers and/or taxpayers to the firm's owners and managers subject to a firm participation or break-even constraint. Armstrong and Sappington (2007) articulate this by specifying an objective function $W=S+\alpha R$, where $W$ is expected social welfare, $S$ equals expected consumers' (including consumers as taxpayers) surplus, $R$ equals the expected rents earned by the owners and managers of the firm (over and above what is needed to compensate them for the total costs of production and the disutility of managerial effort to satisfy the firm viability or participation constraint), and where $\alpha<1$ implies that the regulator places more weight on consumer surplus than on rents earned by the firm. That is, the regulator seeks to extract rent from the firm for the benefit of consumers, subject as always to a firm break-even constraint. In addition, $W$ will be reduced if excessive rents are left to the firm since this will require higher (second-best) prices and greater allocative inefficiency.

Laffont and Tirole $(1986,1993,2000)$ create a social benefit from reducing the rents left to the firm in a different way. In their basic model, consumer welfare and the welfare of the owners and managers of the firm are generally weighted equally. However, one of the instruments available to the regulator is the provision of transfer payments from the government to the firm, which affect the rents earned by the firm. These transfer payments come out of the government's budget and carry a social cost resulting from the inefficiencies of the tax system used to raise these revenues. Thus, for every dollar of transfer payments given to the firm to increase its rent, effectively $(1+\lambda)$ dollars of taxes must be raised, where $\lambda$ reflects the inefficiency of the tax system. Accordingly, by reducing the transfers to the firm over and above what is required to compensate it for its efficient production costs and the associated managerial disutility of effort, welfare can be increased. As noted 
earlier, this setup also leads to a nice dichotomy between incentive mechanisms and the setting of second-best prices for the services sold by the firm. That is, regulators first establish compensation arrangements (define how the firm's budget constraint or "revenue requirements" will be determined) to deal as effectively as possible with adverse selection and moral hazard problems given the information structure assumed. The regulator separately establishes a second-best price structure to deal with allocational efficiency considerations. These prices may not yield enough revenue to cover all of the firm's costs, with the difference coming from net government transfers (or vice versa). In addition, Laffont and Tirole introduce managerial effort (e) as a variable that affects costs. Managers have a disutility of effort ( $U$ ) and must be compensated for it. Accordingly, the utility of management also appears in the social welfare function.

What does the regulator know about the firm ex ante and ex post? The literature that focuses on adverse selection builds on the fundamental paper by Baron and Myerson (1982). There the regulator does not know the firm's cost opportunities ex ante but has information about the probability distribution over the firm's possible cost opportunities. ${ }^{7}$ Nor can the regulator observe or audit the firm's costs ex post. The firm does know its own cost opportunities ex ante and ex post. The firm's demand is known by both the regulator and the regulated firm. There is no managerial effort in these early models of incentive mechanism design. Accordingly, the analysis deals with a pure adverse selection problem with no potential inefficiencies or moral hazard associated with inadequate managerial effort. The regulation in the presence of adverse selection literature then proceeds to consider asymmetric information about the firm's demand function, where the firm knows its demand but either the regulator does not observe demand ex ante or ex post or learns about demand only ex post (Lewis and Sappington 1988a; Riordan 1984).

In light of common US and Canadian regulatory practice, a natural extension of these models is to assume that the regulated firm's actual realized costs are observable ex post, at least with uncertainty. Baron and Besanko (1984) consider cases where a firm's costs are "audited" ex post, but the actual realized costs resulting from the audit are observable by the regulator with a probability less than one. The regulator can use this information to reduce the costs of adverse selection. Laffont and Tirole $(1986,1993)$ consider cases where the firm's realized costs are fully observable by the regulator. However, absent the simultaneous introduction of an uncertain scope for cost reductions through managerial effort, the regulatory problem then becomes trivial - just set prices equal to the firm's realized costs. Accordingly, Laffont and Tirole $(1986,1993)$ introduce managers of the

7. In models that distinguish between fixed and variable costs, the regulator may know the fixed costs but not the variable costs. See Armstrong and Sappington (2004). 
firm who can choose the amount of cost reducing effort that they expend. Managerial effort is not observable by the regulator ex ante or ex post, but realized production costs are fully known to the regulator, as is the managerial "production function" that transforms managerial effort into cost reductions and the managers' utility of effort function. The regulated firm fully observes managerial effort, the cost-reducing effects of managerial effort, and demand. It also knows what managerial utility would be at different levels of effort. Armstrong and Sappington (2004) advance this analysis by considering cases where the regulated firm is uncertain about the operating costs that will be realized but knows that it can reduce costs by increasing managerial effort, though in a way that creates a moral hazard problem but no adverse selection problem. In the face of uncertainty over its costs, they consider cases where the firm may be either risk neutral or risk averse.

What instruments are available to the regulator, and how do the regulator and the regulated firm interact over time? Much of the incentive regulation literature is static. The regulator (or the government through the regulator) can offer a menu of prices (or fixed price contracts) with or without a fixed fee or transfer payment. The menu may contain prices that are contingent on realized costs (which can be thought of as penalties or rewards for performance) in those models where regulators observe costs ex post. Some of these instruments may be costly to utilize (e.g., transfer payments and auditing efforts). The more instruments the regulator has at its disposal and the lower the costs of using them, the closer the regulator will be able to get to the full information efficiency benchmark.

In the two-type case, the optimal regulatory mechanism involves offering the regulated firm a choice between two regulatory contract options. One is a fixed price option that leaves some rent if the firm is a low-cost type but negative rent if it is a high-cost type. The second is a cost-contingent contract that distorts the firm's effort if it is a high-cost type but leaves it no rent. The high-powered scheme is the most attractive to the low-cost type and the low-powered scheme is the most attractive to the high-cost type. The expected cost of the distortion of effort if the firm is a high-cost type is balanced against the expected cost of leaving additional rent to the firm if it is a low-cost type-the fundamental trade-off between incentives and rent extraction.

The two-type example can be generalized to a continuum of types (Laffont and Tirole 1993, 137ff). Assume that $\beta$ indicates the firm's type ordered from low-cost to high-cost opportunities and has a continuous distribution from some lower bound $\beta_{L}$ to some upper bound $\beta_{H}$ with a cumulative distribution $F(\beta)$ and a strictly positive density $f(\beta)$ where $F$ is assumed to satisfy a monotone hazard rate condition so that $F(\beta) / f(\beta)$ is nondecreasing in $\beta .{ }^{8}$ The

8. Most commonly used distributions satisfy this assumption (e.g., uniform and normal distributions). 
regulator maximizes expected social welfare subject to the firm participation and incentive compatibility constraints as before and incentive compatibility requires a mechanism that leaves more rent to the firm the lower is its type $\beta$, with the highest cost type getting no rent, the lowest cost type getting the most rent, and the intermediate type's rent defined by the difference in their marginal costs. Similarly, the effort of the lowest cost type is optimal and the effort of the highest cost type is distorted the most, with intermediate types having smaller levels of distortion (and more rents) as $\beta$ declines toward $\beta_{L}$. In the case of a continuous distribution of types, the optimality conditions are directly analogous to those for the two-type case.

Laffont and Tirole (1993) show that these optimality conditions can be implemented by offering the firm a menu of linear contracts, which in their model are transfer or incentive payments in excess of realized costs (which are also reimbursed), of the form:

$$
t(\beta, c)=a(\beta)-b(\beta) c,
$$

where $a$ is a fixed payment, $b$ is a cost-contingent payment, and $a$ and $b$ are decreasing in $\beta$.

We can rewrite the transfer payment equation in terms of the gross transfer to the firm including the unit cost reimbursement:

$$
\begin{aligned}
& R_{f}=a(\beta)-b(\beta) c+c=a(\beta)+(1-b(\beta)) c, \\
& \text { where } d a l d b>0
\end{aligned}
$$

(for a given $\beta$ a unit increase in the slope of the incentive payment must be compensated by an increase in the fixed payment to cover the increase in production costs),

$$
\text { and } d^{2} a l d b^{2}<0,
$$

(the fixed payment is a concave function of the slope of the incentive scheme; see figure 5.1).

The lowest cost type chooses a fixed price contract with a transfer net of costs equal to $U_{L}$, and the firm is the residual claimant on cost-reducing effort $(b=1)$ As $\beta$ increases, the transfer is less sensitive to the firm's realized costs ( $b$ declines), the rent is lower ( $a$ declines), and the efficiency distortion from suboptimal effort increases.

One way in which regulators can effectively reduce their information disadvantage is by using competitive benchmarks or "yardstick regulation" in the price-setting process. Shleifer (1985) shows that if there are multiple noncompeting but otherwise identical firms (e.g., gas distribution companies in firms in different states), an efficient regulatory mechanism involves setting the price for each firm based on the costs of the other firms. Each individual firm has no control over the price it will be allowed to charge (unless the firms can collude) since it is based on the realized costs of $(n-1)$ other firms. 


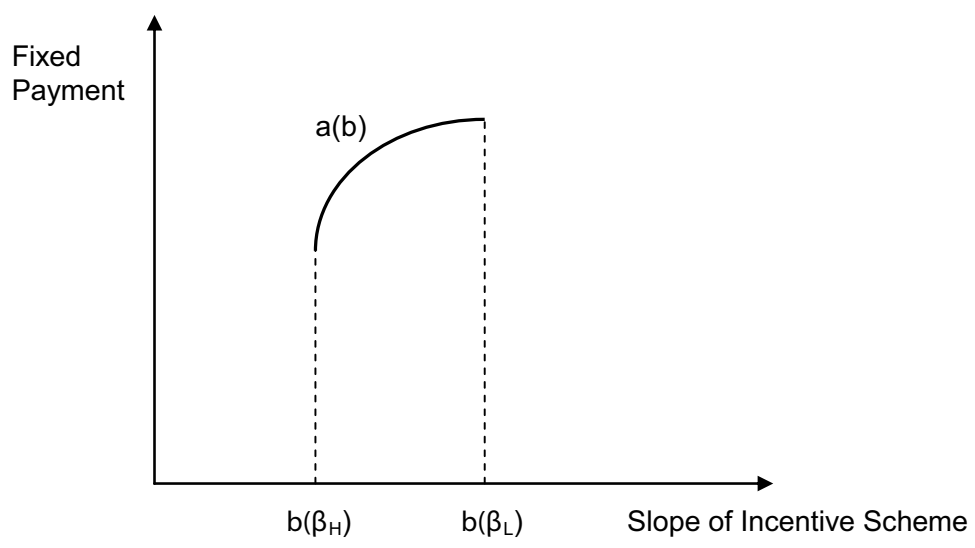

Fig. 5.1 Menu of incentive contracts

Source: Laffont and Tirole (1993, figure 1.5).

Thus, effectively each firm has a fixed price contract and the regulator can be assured that the budget balance constraint will be satisfied since if the firms are identical prices will never fall below their "efficient" realized costs. This mechanism effectively induces each firm to compete against the others. The equilibrium is a price that just covers all of the firm's efficient costs as if they competed directly with one another.

Of course, the regulator is unlikely to be able to find a large set of truly identical firms. However, hedonic regression, frontier cost function estimation, and related statistical techniques can be used to normalize cost variations for exogenous differences in firm attributes to develop normalized benchmark costs (Jamasb and Pollitt 2001, 2003; Estache, Rossi, and Ruzzier 2004). As we shall see following, these benchmark costs can then be used by the regulator in a yardstick framework or in other ways to reduce its information disadvantage, allowing it to use high-powered incentive mechanisms without incurring the cost of excessive rents that would accrue if the regulator had a greater cost disadvantage. However, data to perform this type of benchmarking analysis are not always available, a variety of benchmarking techniques can be utilized, and the failure to integrate cost and quality variables can lead to misleading results (Giannakis, Jamasb, and Pollitt 2004; Jamasb and Pollitt 2001).

Of additional practical interest are issues that arise as we consider the dynamic interactions between the regulated firm and the regulator and the availability and utilization of mechanisms that the regulator potentially has available to reduce its information disadvantage. It is inevitable that the regulator will learn more about the regulated firm as they interact over time. So, for example, if the regulator can observe a firm's realized costs ex post it will learn a lot about its true cost opportunities. Should the regulator use that 
information to reset the prices that the regulated firm receives (commonly known as a "ratchet"; see Weitzman 1980)? Or is it better for the regulator to commit to a particular contract ex ante, which may be contingent on realized costs, but the regulator is then not permitted to use the information gained from observing realized costs to change the terms and conditions of the regulatory contract offered to the firm? Is it credible for the regulator to commit not to renegotiate the contract, especially in light of US regulatory legal doctrines that have been interpreted as foreclosing the ability of a regulatory commission to bind future commissions?

Clearly, if the regulated firm knows that information about its realized costs can be used to renegotiate the terms of its contract ex post, this will affect its behavior ex ante. It may have incentives to engage in less cost reduction in period 1 or try to fool the regulator into thinking it is a high cost firm so that it can continue to earn rents in period 2 . Or if the regulated firm has a choice between technologies that involve sunk cost commitments, will the possibility of ex post opportunism or regulatory expropriation, perhaps driven by the capture of the regulator by other interest groups, affect its willingness to invest in the lowest cost technologies when they involve more significant sunk cost commitments (leading to the opposite of the AverchJohnson effect; see Averch and Johnson 1962; Baumol and Klevorick 1970). These issues are all of considerable importance when applying incentive regulation concepts in practice.

These dynamic issues have been examined theoretically more intensively over time and represent a merging of the literature on regulation with the literature on contracts and dynamic incentive mechanisms more generally (Laffont and Tirole 1988b, 1990, 1993; Baron and Besanko 1987a; Armstrong and Vickers 1991, 2000; Armstrong, Cowan, and Vickers 1994). The impacts of regulatory lag of different durations (Baumol and Klevorick 1970; Klevorick 1973; Joskow 1974) and other price adjustment procedures have been analyzed theoretically as well (Vogelsang and Finsinger 1979; Sappington and Sibley 1988, 1990).

As I will discuss further in the following, one of the regulatory mechanisms utilized extensively in the United Kingdom after its utility sectors were privatized is effectively a fixed price contract (actually a price cap that is adjusted for general movements in input prices and an assumed target rate of productivity growth - a so-called RPI-X mechanism as discussed in detail later) with a ratchet every five (or so) years when the level of the price cap is reset to reflect the current realized (or forecast) cost of service (Beesley and Littlechild 1989; Brennan 1989; Isaac 1991; Sibley 1989; Armstrong, Cowan, and Vickers 1994). It has been observed that regulated firms appear to make their greatest cost reduction efforts during the early years of the price cap period and then exert less effort at reducing costs as the date of the price review proceeding approached (OFGEM 2004a, 2004b, 2004d, 2004e). More generally, the dynamic attributes of the regulatory process and 
how regulators use information about costs revealed by the regulated firm's behavior over time have significant effects on the incentives the regulated firm faces and on its behavior (Gilbert and Newbery 1994).

\subsection{Practical Implementation Issues}

While the theoretical literature on incentive regulation is quite rich, it still provides relatively little direct guidance for empirical application in specific circumstances. Regulators need to find answers to a number of practical questions to apply the theory in practice in the design of actual incentive regulation mechanisms. Among the questions that must be answered are the following:

Where does the regulator's information about the firm's actual costs and the distribution of cost opportunities come from? If regulators are going to apply incentive regulation mechanisms that are cost contingent they must have some consistent mechanism for measuring the regulated firm's actual costs. These costs include operating costs (e.g., labor), the cost of capital investments (e.g., the cost of physical distribution network equipment), and the financial components necessary to transform this capital investment cost stock into a flow of rental or user charges for capital services (e.g., depreciation rates, the opportunity cost of capital, the appropriate debt/equity ratio, income taxes) over time.

Capital cost accounting issues have largely been ignored in the theoretical literature on incentive regulation. Although it has been of limited concern to contemporary economists, any well-functioning regulatory system needs to adopt good cost accounting rules, reporting requirements for costs, output, prices, and other dimensions of firm performance, and enforce auditing and monitoring protocols to ensure that the regulated firm applies the auditing rules and adheres to its reporting obligations. Much of the development of US regulation during the first half of the twentieth century focused on the development of these foundation components required for any good regulatory system that involves cost-contingent regulatory mechanisms. See Joskow (2007) for a more detailed discussion of capital cost accounting principles used in the United States.

Of course, cost is only one dimension of firm performance. Firm performance may also have various "quality" dimensions and there are likely to be inherent trade-offs between cost and quality. If incentives are to be extended to the quality dimension as well, as they should be, then these quality dimensions must be defined and associated performance indicia measured by the firm, reported to the regulator, and must be subject to auditing protocols. Regulators also need information to develop a view about the distribution of cost opportunities, consumer valuations of service quality, and other dimensions of firm performance to implement incentive regulation mechanisms that do not leave too much rent to regulated firms and do not lead to exces- 
sive managerial efficiency. Regulators need to have the resources to develop information about industry performance norms and the causes of variations in the performance of regulated firms. Accordingly, they need the resources to commission industry studies that give them this kind of information so that their information disadvantage can be reduced.

Should the regulator offer the regulated firm a menu of contracts or a specific contract with a single set of values for $\mathrm{a}$ and $\mathrm{b}$ as discussed earlier? The Laffont-Tirole framework implies that firms should be offered a menu of cost-contingent contracts from which they can choose. The menu forces the firm to reveal its type ex post and allows for a better balance of efficiency and rent extraction than would a single linear incentive contract designed ex ante based on the same information and subject to the same budget balance constraints. However, it appears that regulators typically offer firms only a single regulatory contract, and when the contract is cost contingent it is typically linear (Schmalensee 1989b). I am aware of two situations in which regulated firms were offered a menu of cost-contingent or sliding scale contracts. The first relates to the system operator (SO) incentive schemes that have been offered to the electric transmission system operator in England and Wales, discussed in the following. The second is the menu of sliding scale mechanisms offered to the electric distribution companies in the United Kingdom for determining future capital expenditure allowances and associated user charges for capital services pursuant to the review and resetting of electricity distribution charges issued in late 2004 for distribution charges that would be in effect from April 1, 2005 until March 31, 2010. These menus are discussed in more detail below as well. However, there may be more use of a de facto menu of contracts approach than first meets the eye when we take the attributes of the regulatory review process itself into account. The final regulatory mechanism applied to a regulated firm is often the result of formal and informal negotiations involving proposals by the regulator's staff, the regulatory firm, and interested third parties (Joskow 1973, 1974; Doucet and Littlechild 2006). This process may have similarities to the regulator's offer of a menu of contracts in the sense that the parties negotiate over the attributes of the incentive mechanism. We see only the final outcome of these negotiations.

What benchmarks are to be used to arrive at starting values for the regulated firm's costs, revenues, and other performance indicia, and how are these benchmarks adjusted over time? In some cases regulators accept the firm's current levels of costs and other dimensions of performance and focus on benchmarks for performance improvements, effectively benchmarking the firm against its historical performance. This approach reflects the assumption that the firm can do better than it has in the past, but still leaves open the question of performance improvement norms. Another approach is to benchmark the firm's current performance using appropriate comparisons with other similarly situated firms, properly adjusting for differences in the 
cost opportunities and demand patters faced by similar but not identical comparator firms. Where there is not a set of reasonable comparator firms to draw upon, regulators may rely on engineering and management "experts" to study the firm's performance and opine on cost improvement opportunities and the associated uncertainties, perhaps drawing analogies from components of firms in other industries.

What should be the power of the incentive scheme? If the regulator offers a menu of cost-contingent contracts, the height and the slope of the incentive scheme must be defined ( $a$ and $b$ above). If the regulator applies a single incentive mechanism, both the fixed component and the "sharing" or "sliding scale" fraction must be defined. If the regulatory mechanism is a price cap, both the starting values for prices or the average price level ( $p_{o}$ for UK regulation of electric, gas, and water distribution and transmission networks) and the " $x$ " intertemporal adjustment factor must be defined. In addition, an appropriate inflation index (RPI in the United Kingdom) must be identified.

In practice, incentive regulation mechanisms typically also have "resets" or "ratchets" and the period of "regulatory lag" between price reviews needs to be defined. As the review period gets longer the power of the incentive mechanism increases and vice versa. Finally, many incentive regulation mechanisms used in practice have caps and floors that effectively define a collar on the operation of the mechanism. So, for example, a cap and floor are often applied that limit the gains and the losses that the regulated firm can incur under the incentive mechanism. Once the cap or floor is hit the mechanism effectively defaults to pure cost-of-service regulation or to a renegotiation of the regulatory contract. The rationale for the use of caps and floors superimposed onto a sliding scale scheme is not immediately obvious from incentive regulation theory and is likely to have poor incentive properties around the points where the collar kicks in. The use of caps and floors is probably best thought of as a way for regulators to recognize the range of outcomes anticipated in the design of the mechanism and the associated starting values and sharing fractions that have been defined. When the caps and floors are hit this effectively triggers a renegotiation, reset, or ratchet process.

Should the incentive mechanism be comprehensive or "partial"? There are multiple dimensions of firm performance defined by cost and quality indicia and the trade-offs between them. Most regulated firms supply multiple products for which demand and cost attributes vary. There are also multiple dimensions of firm costs with different adjustment lags. Operating costs can be adjusted relatively quickly, while capital costs are often long lived and can be economically adjusted much more slowly. Moreover, both the level and adjustment opportunities for operating costs depend upon the attributes of the legacy stock of capital and investments in new facilities and can both expand the firm's capacity to supply particular products and affect its oper- 
ating costs. Capital and operating costs are inherently interdependent with varying adjustment lags. As a practical matter, the line between an operating cost and a capital cost may not be well defined except by clear accounting rules. A hammer that lasts for five years may be expensed while software that has a useful life of three years may be capitalized. Under some incentive regulation mechanisms this creates opportunities for gaming by expensing capital costs or capitalizing operating costs.

Ideally, a comprehensive incentive regulation mechanism that consistently integrates all cost and quality relationships at a point of time and over time would be applied. However, as a practical matter this often places very challenging information and implementation burdens on the regulator. Partial mechanisms or a portfolio of only loosely harmonized mechanisms are often used by regulators. Operating and capital cost norms and targets are typically developed separately and the effective power of the incentive scheme applicable to operating and capital costs may vary between them. Separate incentive mechanisms may be applied to measures of quality than to measures of total operating and capital costs. This reality represents perhaps the most significant variation between received incentive regulation theory and incentive regulation in practice.

\subsection{Implementation in Practice to Electricity and Gas Networks}

\subsubsection{Early Applications}

Although the theoretical literature on incentive regulation is fairly recent, we can trace the earliest applications of incentive regulation concepts back to the early regulation of the manufactured gas distribution sector $^{9}$ (town gas) in England in the mid-nineteenth century (Joskow and Schmalensee 1986; Hammond, Johnes, and Robinson, 2002). A sliding scale mechanism in which the dividends available to shareholders were linked to increases and decreases in gas prices from some base level was first introduce in England in 1855 (Hammond, Johnes, and Robinson, 2002, 255). The mechanism established a base dividend rate of 10 percent. If gas prices increased above a base level the dividend rate was reduced according to a sharing formula. However, if gas prices fell below the base level the dividend rate did not increase (a "one-way" sliding scale). The mechanism was made symmetric in 1867. Note that the mechanism was not mandatory and it was introduced during a period of falling prices (Hammond, Johnes, and Robinson, 2002, 255-56). A related profit-sharing mechanism (what Hammond, Johnes, and Robinson call the "Basic Price System") was introduced in 1920 that pro-

9. This is before the development of natural gas. "City gas" was manufactured from coal by local gas distribution companies. At the time there were both private and municipal gas distribution companies in operation in England. 
vided a minimum guaranteed 5 percent dividend to the firm's shareholders and shared changes in revenues from a base level between the consumers, the owners of the firm, and the firm's employees. Specifically, this mechanism established a basic price $p_{b}$ to yield a 5 percent dividend rate. This dividend rate was the minimum guaranteed to the firm. At the end of each financial year the firm's actual revenues $(R)$ were compared to its basic revenues $R_{b}=$ $p_{b}$ times the quantity sold. The difference between $R$ and $R_{b}$ was then shared between consumers, investors, and employees, apparently subject to the constraint that the dividend rate would not fall below 5 percent.

In the early twentieth century, US economists took note of the experience with sliding scale mechanisms for local manufactured gas utilities in England, but appear to have concluded that they were not well matched to the regulation of electricity and telephone service (and other sectors) where demand and technology were changing fast and future costs were very uncertain (Clark 1913). Cost-of-service regulation (with regulatory lag, prudence reviews, and public planning processes) evolved initially as the favored alternative in the United States and other countries with private (rather than state-owned) regulated monopolies and the experience in England during the nineteenth and early twentieth centuries was largely forgotten by both regulators and students of regulation.

State public utility commissions in the United States began to experiment with formal performance based regulation mechanisms for electric utilities in the early 1980s. The early programs were targeted at specific components of an electric utility's costs or operating performance such as generation plant availability, heat rates, or construction costs (Joskow and Schmalensee 1986; Sappington et al. 2001). Formal comprehensive incentive regulation mechanism have been slow to spread in the US electric power industry (Sappington et al. 2001), though rate freezes, rate case moratoria, price cap mechanisms, and other alternative mechanisms have been adopted in many states, sometimes informally, since the mid-1990s.

\subsubsection{Price Cap Mechanisms: General Considerations}

Beginning in the mid-1980s a particular form of incentive regulation was introduced for the regulated segments of the privatized electric gas, telephone, and water utilities in the United Kingdom, New Zealand, Australia, and portions of Latin America as well as in the regulated segments of the telecommunications industry in the United States. ${ }^{10}$ The primary (but not the only) mechanism chosen was the "price cap" (Beesley and Littlechild 1989; Brennan 1989; Armstrong, Cowan, and Vickers 1994; Isaac 1991). Under price cap regulation the regulator sets an initial price $p_{o}$ (or a vector

10. The United States is behind many other countries in the application of incentive regulation principles to electric distribution and transmission, though their use is slowly spreading in the United States beyond telecommunications. 
of prices for multiple products). This price (or a weighted average of the prices allowed for firms supplying multiple products or different types of customers) is then adjusted from one year to the next for changes in inflation (rate of input price increase or RPI) and a target productivity change factor $x$. Accordingly, the price in period 1 is given by:

$$
p_{1}=p_{o}(1+\mathrm{RPI}-x) \text {. }
$$

Typically, some form of cost-based regulation is used to set $p_{o}$. The price cap mechanism then operates for a preestablished time period (e.g., five years). ${ }^{11}$ At the end of this period a new starting price $p_{o}$ and a new $x$ factor are established after another cost-of-service and prudence or efficiency review of the firm's costs. That is, there is a prescheduled regulatory ratchet built into the system.

As discussed earlier, in theory, a price cap mechanism is a high-powered "fixed price" regulatory contract that provides powerful incentives for the firm to reduce costs. Moreover, if the price cap mechanism is applied to a (properly) weighted average of the revenues the firm earns from each product it supplies, the firm has an incentive to set the second-best prices for each service (Laffont and Tirole 2000; Armstrong and Vickers 1991) given the level of the price cap. It is also fairly clear that pure "forever" price cap mechanisms are not optimal from the perspective of an appropriate tradeoff between efficiency incentives and rent extraction (Schmalensee 1989b).

In practice, price cap mechanisms apply elements of cost-of-service regulation, yardstick competition, and high-powered "fixed price" incentives, plus a ratchet. Price caps on operating costs or capital plus operating costs are often one component of a larger portfolio of incentive mechanisms. As I will show presently, the details of constructing a price cap mechanism for electric distribution and transmission networks are more complicated than is often thought. Moreover, the regulated electric or gas distribution firm's ability to determine the structure of prices under an overall revenue cap is typically limited. Price caps applied to electricity and gas distribution and transmission are used primarily as an incentive mechanism, not as a mechanism to induce optimal pricing. In telecommunications, regulated firms are given more pricing freedom so that price cap mechanism affects both performance incentives and pricing incentives.

It is worth noting again that in an ongoing regulated firm context, a pure "forever" price cap without any cost sharing (i.e., without a sliding scale mechanism) is not likely to be optimal given asymmetric information and uncertainty about future productivity opportunities (Schmalensee 1989b).

11. Many implementations of price cap regulation also have " $z$ " factors. $Z$ factors reflect cost elements that cannot be controlled by the regulated firm and are passed through in retail prices. For example, in the United Kingdom, the charges distribution companies pay for connections to the transmission network are treated as pass-throughs. Changes in property tax rates are also often treated as pass-throughs. 
Prices would have to be set too high to satisfy the firm participation constraint and too much rent would be left on the table for the firm. The application of a ratchet from time to time that resets prices to reflect observed costs is a form of cost-contingent dynamic regulatory contract. It softens costreducing incentives but extracts more rents for consumers in the long run.

A natural question to ask about price cap mechanisms is where does $x$ (and perhaps $p_{o}$ ) come from (Bernstein and Sappington 1999)? Conceptually, assuming that RPI is a measure of a general input price inflation index, $x$ should reflect the difference between the expected or target rate of total factor productivity growth for the regulated firm and the corresponding productivity growth rate for the economy as a whole and the difference between the rate of change in the regulated firm's input prices and input prices faced by firms generally in the economy. That is, the regulated firm's prices should rise at a rate that reflects the general rate of inflation in input prices less an offset for higher (or lower) than average productivity growth and an offset for lower (or higher) input price inflation. Unfortunately, the theory advanced by Bernstein and Sappington is rarely applied in practice.

In early applications in the United States, the computation of $x$ was often fairly ad hoc. The initial application of the price cap mechanism by the Federal Communications Commission (FCC) to AT\&T's intercity and information services used historical productivity growth and added an arbitrary "customer dividend" to choose an $x$ that was larger than the historical rate of productivity growth. However, the expectation here was that the need for regulation would be transitory and would be phased out for AT\&T's services as competition expanded. In England and Wales and some other countries, statistical benchmarking methods have come into use to help determine the relative efficiency of individual firms' operating costs and service quality compared to their peers. This information can then be used as an input to setting values for both $p_{o}$ and $x$ (Jamasb and Pollitt 2001, 2003; OFGEM 2004a) to provide incentives for those far from the efficiency frontier to move toward it and to reward the most efficient firms in order to induce them to stay on the efficiency frontier, in a fashion that is effectively an application of yardstick regulation. A variety of empirical methods have been applied to identify an operating cost efficiency frontier and to measure how far from this operating cost efficiency frontier individual regulated firms lie. The value for $x$ is then defined in such a way as to move the firms to the frontier over a prespecified period of time (e.g., five years). These methods have recently been expanded to include quality of service considerations (Giaanakis, Jamasb, and Pollitt 2004). Benchmark rankings of relative performance may change significantly when quality attributes are introduced. Accordingly, benchmarking cost and quality as separable attributes is clearly problematic.

The extensive use of periodic "ratchets" or "resets to cost" along with price cap mechanisms reflect the difficulties of defining a fixed long-term 
value for $p_{o}$ and $x$ ex ante and the standard trade-offs between efficiency incentives, rent extraction, and firm viability constraints. These periodic ratchets necessarily dull incentives for cost reduction, however. Note in particular that with a predefined five-year ratchet, a dollar of cost reduction in year one is worth a lot more than a dollar of cost reduction in year four since the cost savings are retained by the firm only until the next reset anniversary (OFGEM 2004d, 2004b, 2004c).

Although it is not discussed too much in the empirical literature, the development of the parameters of price cap mechanisms using statistical benchmarking methods have typically focused primarily on operating costs only. Capital cost allowances are established through more traditional utility planning and cost-of-service regulatory accounting methods including the specification of a rate base (regulatory asset value or RAV), depreciation rates, debt and equity costs, debt/equity ratios, tax allowances, and so forth. Since operating costs for distribution networks are often a smaller fraction of total costs than are capital-related costs, the focus on operating costs (or so-called controllable costs) is potentially misleading. In addition, it is widely recognized that a pure price cap mechanism provides incentives to reduce both costs and the quality of service (Banerjee 2003). Accordingly, price cap mechanisms are increasingly accompanied either by specific performance standards and the threat of regulatory penalties if they are not met or formal PBR mechanisms that set performance standards and specify penalties and rewards for the firm for falling above or below these performance norms (OFGEM 2004b, 2004c; Sappington 2003; Ai and Sappington 2002; Ai, Martinez, and Sappington 2004).

\subsubsection{The Basic Price Cap Mechanism for Electric Distribution Companies: The UK Implementation ${ }^{12}$}

There are fourteen electric distribution companies in the United Kingdom, several of which are under common ownership within a holding company structure, yielding seven firms controlling fourteen electric distribution networks. These companies, which are referred to as regional electricity companies, or RECs, provide delivery services in specific geographic franchise areas to transport electricity from points of interconnection with the high voltage transmission network to points of interconnection with final consumers. Their total revenues and the associated prices for using their networks are regulated by the UK Office of Gas and Electricity Markets (OFGEM). The distribution companies themselves provide only delivery services and do not contract to buy or produce electricity for resale to final customers, a competitive function referred to as "electricity supply" in the United Kingdom,

12. After two working paper versions of this chapter (2005 and 2006) were widely distributed, Jamasb and Pollitt (2007) released a working paper that also examines aspects of the 2004 review of electric distribution network prices and incentive mechanisms in the United Kingdom. As a result, there is some overlap between portions of this chapter and their paper. 
though they may have functionally separated or "ring fenced" supply affiliates that do so. The discussion that follows refers primarily to OFGEM's 2004 review of electric distribution charges, which established prices and price adjustment formulas for each REC for the period April 1, 2005, until March 31, 2010. The 2009 price review established electric distribution prices and incentive formulas for the period April 1, 2010, until March 31, 2015 (OFGEM 2009). The basic approach did not change very much from the earlier price reviews, though some changes were made to accommodate the UK's low-carbon policies. A complete review of the procedures for setting electric distribution charges, referred to as the RPI-X@20 project, is focused on integrating REC prices and incentives to align them with the UK's lowcarbon policies. This review is ongoing as of this writing (OFGEM 2010).

The primary mechanism used to determine the total revenues that a regulated electricity distribution firm is permitted to recover from its prices for delivery service (the allowed revenue and associated average price level) is a price cap mechanism that sets an initial starting value for revenues $\left(p_{o}\right)$, specifies an exogenous input price index (RPI) for adjusting revenues and price levels from one year to another for general inflation, and a productivity factor $x$, which further adjusts revenues and delivery prices over time. The value for $x$ can be either positive or negative or zero. This regulatory framework establishes values for $p_{o}, x$, and the relevant RPI index once every five years. Thus, the basic parameters that determine distribution delivery prices and their adjustment over time are determined once every five years and then "reset" in a new regulatory hearing.

The $p_{o}$ and $x$ values are developed based on a review of the relative efficiency of each firm's operating costs, the firm's current capital stock or rate base (adjusted for depreciation and inflation since the previous price review) - referred to in the United Kingdom as the firm's regulatory asset value (RAV) - forecasts of future capital additions required to provide target levels of service quality, the application of depreciation rates to existing and new capital investments, estimates of the cost of the firm's debt and equity capital, assumptions about the firm's dept/equity ratio, tax allowances, and other variables. The allowed revenues for the firm over the fiveyear period are then the sum of allowed operating costs and allowed capital costs (depreciation and after-tax return on investment) determined in each year.

Variables $p_{o}$ and $x$ are chosen so that the present discounted values of revenues over the five-year period is equal to the present discounted value of the total operating and capital-related charges that have been allowed for each distribution company for the five-year price review period. The choice of the specific values for $p_{o}$ and $x$ that satisfies this present discounted value property is a matter of judgment (OFGEM 2004c). Historically, this choice was driven by the notion that the regulated firms should be given some time to achieve reductions in operating costs to the efficient benchmarked level, 
leading to a relatively high initial value for $p_{o}$ and a value of $x$ that brings operating costs to their efficient levels over the period the price cap is in effect. OFGEM abandoned this "glide path" approach in its 2004 price review for electric distribution companies, perhaps because the initial value of $p_{o}$ would have otherwise increased significantly as a result of a large increase in target investment expenditures (OFGEM 2004c).

Because the overall price cap covers both capital and operating costs, the ultimate value of $x$ depends on both the target efficiency improvements in operating costs and the forecast carrying charges on the existing RAV, plus the carrying charges on allowed levels for future investments over the five-year price control period. So, for example, real operating costs may be targeted to fall over time, implying a value of $x$ in the RPI-X formula of, say, 1.5 percent per year. However, if capital-related costs are forecast to increase by 1.5 percent per year, the value of $x$ used in the price cap mechanism over the five-year period would be negative (yielding trajectory of increasing real prices) since capital-related charges, including taxes, are typically about double the allowed operating costs for a UK electric distribution company.

To illustrate the application of these principles, I describe below the process used by OFGEM in the 2004 review of prices for electric distribution companies that established the 2005 to 2010 electric distribution prices; see OFGEM (2009) for details on the subsequent review that established electricity distribution prices for the period 2010 to 2015 and OFGEM (2010) for the RPI-X@20 project, which is developing new approaches to setting electricity distribution rates and incentives beginning in 2015. In the 2004 price review, each firm's price cap was set so that the value of $x$ is zero, implying that prices would rise based on changes in RPI only. As can be seen from table 5.1, there was a large range in the change in $p_{o}$ allowed at the beginning of the new price control period among the fourteen distribution companies ( -9 percent to +9 percent) with an average increase of $p_{o}$ of 1.3 percent from levels prevailing at the end of the previous price review period (OFGEM 2004a). Table 5.1 also summarizes the negotiation process that led to the final proposals. Accordingly, for each distribution company the initial level of allowed total revenues increased with the rate of inflation, with $p_{o}$ set for each company so that the present discounted value of future revenues was equal to the present discounted value of the sum of target operating and capital costs over the five-year period. The choice of a zero value for $x$ does not imply that there were no improvements in operating cost efficiency built into the mechanism. The target improvements in operating costs were built into the total allowed cost forecasts and reflected in the choice of $p_{o}$ given OFGEM's decision to have a flat real price trajectory over the 2005 to 2009 price period.

Since there are fourteen distribution companies in the United Kingdom, the opportunity to perform statistical analyses of how operating costs vary with various causal factors and to estimate variations in efficiency across 
Table 5.1

UK Electric distribution price caps, 2005-2010 $(x=0)$ : OFGEM's initial and final proposals for $p_{o}$

\begin{tabular}{lccccc}
\hline & $\begin{array}{c}\text { June initial } \\
\text { proposals } \\
\%\end{array}$ & $\begin{array}{c}\text { Change } \\
\%\end{array}$ & $\begin{array}{c}\text { September } \\
\text { update } \\
\%\end{array}$ & $\begin{array}{c}\text { Change } \\
\%\end{array}$ & $\begin{array}{c}\text { November } \\
\text { final proposals } \\
\%\end{array}$ \\
DNOs & -6.5 & 2.0 & -4.5 & 1.6 & -2.9 \\
\hline CN-Midlands & -10.8 & 3.3 & -7.5 & 1.8 & -5.7 \\
CN-East Midlands & -1.8 & 7.4 & 5.6 & 2.4 & 8.0 \\
United Utilities & -11.5 & 8.6 & -2.9 & -0.8 & -3.7 \\
CE-NEDL & -14.7 & 1.8 & -12.9 & 3.7 & -9.2 \\
CE-YELD & -0.2 & 1.8 & 1.6 & -0.1 & 1.5 \\
WPD-South West & 1.7 & 5.6 & 7.3 & -1.1 & 6.2 \\
WPD-South Wales & -2.5 & -1.7 & -4.2 & 1.8 & -2.4 \\
EDF-LPM & -3.7 & 6.7 & 3.0 & 4.2 & 7.2 \\
EDF-SPN & -4.6 & 2.5 & -2.1 & 2.0 & -0.1 \\
EDF-EPN & 8.4 & 2.2 & 10.6 & 1.3 & 11.9 \\
SP Distribution & 4.0 & -9.5 & -5.5 & -0.4 & -5.9 \\
SP Manweb & -0.1 & 2.8 & 2.7 & 1.2 & 3.9 \\
SSE-Hydro & 6.1 & 3.1 & 9.2 & 0.1 & 9.3 \\
SSE-Southern & $-\mathbf{2 . 5}$ & $\mathbf{2 . 5}$ & $\mathbf{0 . 0}$ & $\mathbf{1 . 3}$ & $\mathbf{1 . 3}$ \\
Average & & & & & \\
\hline
\end{tabular}

Source: OFGEM (2004d).

Notes: The $p_{o}$ figures for November include allowances for Innovation Funding Incentive (IFI). Those for June and September do not include IFI.

${ }^{a}$ For comparability, EDF $-\mathrm{SPN}$ is shown on the basis of $x=0$. Actual $p_{o}$ will be 3.1 percent, with RPI +2 .

firms readily presents itself. A variety of statistical analyses have been used by OFGEM to arrive at operating cost targets for each of the electric distribution companies (OFGEM 2004a). These methods are now reasonably well-developed and understood by the regulated firms and third parties. During the five-year price control period, the firms are (in principle) the full residual claimants on variations between the target and the actual operating costs.

Despite the fact that capital carrying costs are roughly twice the operating costs for electric distribution companies, the benchmarking methods for determining allowed capital expenditures have been much less well developed than are those for operating costs. Of course, during any particular review period the future stream of allowed carrying charges associated with the stock of capital investments is heavily influenced by historical investments that have been included in the RAV in the past, just like under rate of return regulation. During a new price review, the carrying charges for the historical components of the RAV are affected only by the choice of the allowed returns on debt and equity and the debt/equity ratio assumed for each firm, as well as any changes in depreciation rates. During a new price review, however, future capital investments are still a variable cost that can 
be influenced by the capital expenditure allowances approved by the regulator and built into the future allowed capital carrying charges. Accordingly, much of the focus of the price review is on the approval of a target capital expenditure schedule for the next five-year period. Future investments in capital facilities do not have an insignificant effect on future costs and prices, especially in light of the fact that in the 2004 price review, OFGEM was presented with increases in capital expenditures that averaged over 50 percent more than had been approved for the previous five-year price period (OFGEM 2004a, 2004d).

Formal statistical benchmarking studies of the type that are now applied to operating costs (so-called controllable costs) were not applied to determine allowed investment costs over the next price cap period for each electric distribution company. The appropriate investment program may vary widely depending on variables like customer growth rates, load growth rates, equipment ages and replacement expenditures, underground versus aboveground facilities, service quality improvement needs, and so forth, with little necessary relationship to recent historical trends. Indeed, the rate of investment in electricity network infrastructure has historically been quite cyclical. As a result, it has proven difficult to develop useful statistical benchmarks for future capital additions. Instead, each of the regulated firms presents a proposed capital investment budget to the regulator and the regulator retains engineering consultants to evaluate the proposals and takes evidence from third parties, which use the distribution networks as well. This has historically been a rather contentious process, sometimes yielding significant differences between what the companies claim they need and what the consultants claim they need to meet their legal responsibilities to provide safe and reliable service efficiently.

Regulatory judgments about allowances for future capital expenditures have become more sensitive issues for regulators in the United Kingdom (and the United States) as reliability considerations have become of greater political importance, as excess capacity has been squeezed out of the legacy capital stock, and as the large amount of infrastructure investment made in the 1950s and 1960s reaches the end of its useful life. In the 2004 review, OFGEM adopted an innovative "menu" of sliding scale mechanisms approach to resolve the asymmetric information problem faced by the regulator as she tries to deal with differences between the firms' claims and the consultants' claims (OFGEM 2004d) about future capital investment requirements to meet reliability targets. The sliding scale menu allows firms to choose between getting a lower capital expenditure allowance but a higher powered incentive (and a higher expected return on investment) that allows them to retain more of the cost reduction if they can beat the target expenditure levels or a higher capital expenditure allowance combined with a lower powered sliding scale mechanism and lower expected return (OFGEM 
2004d). The sliding scale mechanism is based on the difference between the allowed capital expenditure target chosen by the firm from the menu and the firm's actual capital expenditures during the five-year price cap period.

The menu of sliding scale incentives adopted in 2004 is reproduced as table 5.2. The values for the sharing fractions are based on the ratio of the distribution company's (DNO) choice of capital expenditure target and that recommended by OFGEM's consultant (PB Power). These ratios vary between 100 and 140. For example, in table 5.2, if a firm agrees to accept a capital expenditure budget equal to 105 percent of the consultant's recommendation (PB Power $=100$ in table 5.2) it would also be choosing the sliding scale in the first column. It would get a base bonus of 2.5 percent of its target income. If its actual expenditures turned out to be 70 percent of the target (through efficiencies) during the price control period it would get a 16.5 percent increase in its income as a reward. If the firm greatly exceeded the target and realized capital expenditures of 140 percent of the target, its income was reduced by 11.5 percent from the target.

This is the most direct and extensive application of Laffont and Tirole's menu of cost-contingent contracts result that I have seen. However, it appears to be the case that the sliding scale scheme for capital expenditures was integrated into the price cap mechanism in a way that makes the power of the incentive scheme for capital expenditures different from the power of the incentive scheme applied to operating costs.

The process is as follows: once the capital investment target for the price control period is determined, these investments are added to the starting value for the RAV or rate base as they are made. Depreciation charges for both the historical and new investments are then calculated for each future year. The depreciation charges are a current capital expense in each year and are simultaneously deducted from the RAV. An allowed rate of return equal to the firm's weighted average real cost of capital before tax adjustments is determined and applied to the RAV in each year. This yields a five-year cash flow profile of real capital service charges reflecting depreciation on historical and allowed future investments and the firm's real opportunity cost of capital, to which capital related taxes are added (see table 5.3). As discussed further below, the details of these computations for capital-related cost allowances are matched to the inflation-adjusted price cap mechanism, but the basic concepts are quite similar to those applied to turn capital investments into a flow of capital service costs under traditional rate-of-return regulation (Joskow 2005).

The allowed capital charges for each year are then added to the allowed operating cost expenses for that year to yield the target total costs for each year of the price control period. This process leads to a set of future allowed real operating and capital-service related costs that will automatically be adjusted in nominal terms each year by the realized rate of inflation in the RPI index chosen. A $p_{o}$ and $x$ value are chosen that together yield allowed 


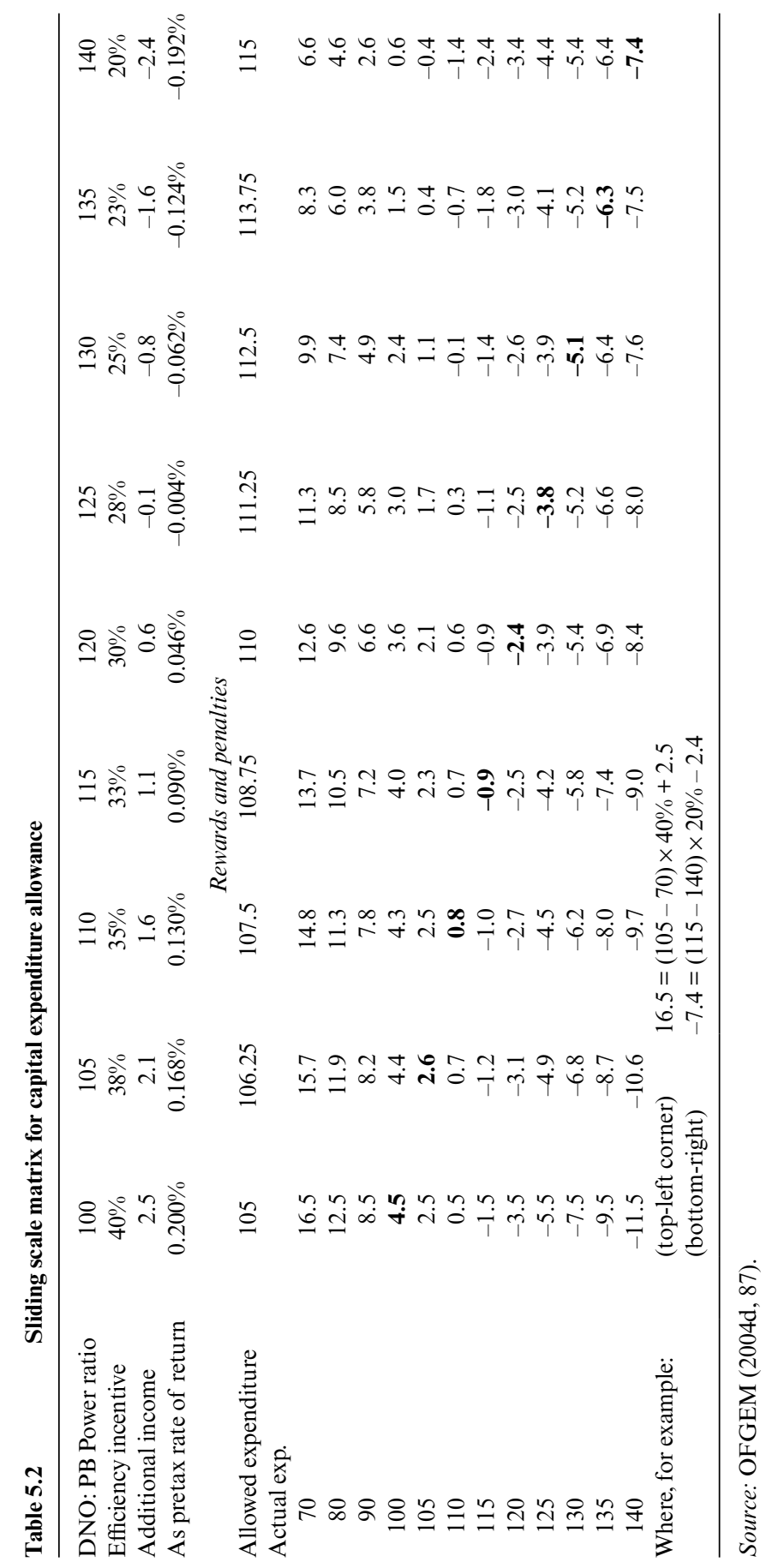


Table 5.3

OFGEM cost of capital assumptions

\begin{tabular}{lcc}
\hline & $\begin{array}{c}\text { Midpoint } \\
\text { (initial proposals and } \\
\text { September update) (\%) }\end{array}$ & Final proposals (\%) \\
\hline Cost of debt & 4.1 & 4.1 \\
Cost of equity & 7.25 & 7.5 \\
Gearing & 60 & 57.5 \\
Vanilla WACC & 5.4 & 5.5 \\
Posttax $_{\text {Pretax }^{\mathrm{a}}}$ & 4.6 & 4.8 \\
\hline
\end{tabular}

Source: OFGEM (2004d, 109).

Notes: WACC $=$ weighted average cost of capital.

${ }^{a}$ Based on a traditional tax wedge approach; compares to 6.5 percent in the previous electricity distribution price control review and 6.25 percent in the last Transco price control review; equivalent to approximately 8 percent, taking account of actual tax allowances proposed.

revenues whose present discounted value is equal to the present discounted value of allowed costs. OFGEM's decision to set $x$ to zero has the effect of "backloading" the revenues toward the end of the price review period. An example of what the various operating and capital cost components look like for one distribution company (United Utilities) is displayed in table 5.4.

There are a number of issues that have not been fully resolved in this price-setting and incentive mechanism specification process. First, as already noted, the five-year ratchet potentially leads to differential incentives for cost reduction depending on how close the firm is to the next price review. OFGEM indicated that it was aware of this problem and committed to allowing firms to keep the benefits of "outperformance" (and presumably the costs of underperformance) for a full five years regardless of when during the five-year review period the outperformance actually occurs. For capital expenditures, OFGEM adopted a formula for rolling adjustments in the value of capital assets used for regulatory purposes (regulatory asset value or RAV) so that outperformance or underperformance incentives and penalties are reflected in prices for a five-year period. Although OFGEM made a commitment to allow operating cost (OPEX) savings to be retained for five years, it did not adopt a formal rolling OPEX adjustment mechanism in the 2004 review, due to imperfections in the operating cost accounting and reporting protocols (OFGEM 2004f). Instead, OFGEM started a process to develop a better uniform system of accounts and reporting requirements to facilitate improvements in the incentive regulation mechanisms.

A second set of issues involves potential asymmetries between the treatment of operating costs and capital costs. The power of the incentive schemes for operating costs and capital costs appears to be different for at least two reasons. First, the sliding scale mechanism applies to capital cost variations 
Allowed 2005 costs (year 1) for one UK distribution company

\begin{tabular}{lrl}
\hline & Emillions & \\
\hline Operating costs & 67.0 & Change in $p_{o}=+8.0 \%$ \\
Capital charges & 103.5 & $x=0$ \\
Tax allowances & 16.0 & \\
Capex incentives & 3.4 & \\
Opex incentives & 1.4 & \\
Pensions & 16.0 & \\
Other & 1.5 & \\
Total & 212.3 & \\
\hline
\end{tabular}

Source: OFGEM (2004d, 127).

but not operating cost variations. In addition, there is not a well-defined line between what is an operating cost that is expensed in a single year and what costs can be capitalized. The firms may have incentives to capitalize operating costs to beat the operating cost incentives during the current review period in the hope that they will be included in the RAV during the next review period. OFGEM made efforts to better define rules for capitalizing expenditures to deter this kind of gaming a priority. Second, when there is capital cost overspending the firm gets another crack to recover at least the undepreciated portion of these expenditures, beginning in the next price review. Capital expenditures have lives that are typically much longer than the five-year review period. How should capital expenditures that exceed or fall short of targets be treated in the next price review? Ordinarily these variances in capital expenditures may be handled through the incentive mechanism discussed earlier, including the impact of the rolling RAV calculation. However, firms can try to make the case that overspending was justified and get it fully included in the next price review, and OFGEM may claw back benefits of underspending that were due to reductions in service rather than efficiencies. Obviously, these adjustments may be quite subjective and need to be evaluated on a case by case basis.

A third set of issues relates to incentives to reduce both operating and capital costs today to increase profits during the current price control period, but with the result that service quality deteriorates either during the current review period or in subsequent periods. Deferred maintenance (e.g., tree trimming) and deferred capital expenditures may lead to the deterioration of service quality in either the short run or the long run or both. Regulated firms may hope that they can use adverse service quality trends to argue for higher allowances for operating and capital costs in future price reviews. The UK regulatory process tries to deal with the relationships between operating and capital cost expenditures and service quality in two ways. First, there are service quality performance norms and incentives that I will discuss presently. Second, OFGEM reserves the right to "claw back" capital cost savings 
if they are clearly not the result of efficiencies but rather reflect efforts to cut services in the short run or the long run. This is not an ideal approach since operating expenditures, capital expenditures, and service quality are related in complex ways over time and space. Indeed, it sounds like the "prudence reviews" that are a component of traditional cost-of-service regulation in the United States. Moreover, operating cost benchmarking studies that do not take service quality and the quality of the capital stock into account can lead to misleading conclusions (Giannakis, Jamasb, and Pollitt 2004).

There is a final issue involving capital cost accounting that has been addressed properly in the United Kingdom, but not in all countries that have implemented price cap mechanisms. When a price cap mechanism (RPI-X) is applied to capital costs, the calculation of the amortization formula for capital (depreciation, rate of return on investment) and the valuation of the capital stock (rate base or RAV) need to be done in a particular way to ensure that there is not over- or underpayment for capital services over the lives of capital investments. Specifically, at the time of a price review the RAV (original cost of capital investments less depreciation) should be adjusted for inflation that has occurred since the last price review, and the allowed rate of return on the RAV during the price review period should be based on the real cost of debt and equity capital net of taxes, with tax allowances then added back in. Because prices are based on both operating and capital costs, the RPI-X formula essentially yields a nominal return equal to the real cost of capital plus the rate of inflation. Capital-related charges rise with the rate of inflation in this case and this is consistent with the RAV rising with the rate of inflation, together yielding an approximation to the economic depreciation rate (depending exactly on how the depreciation rates are set; Joskow 2007; Schmalensee 1989a). Simply bolting a price cap mechanism onto the capital cost accounting formulas used in the United States (Joskow 2007) would lead to the wrong result since regulated prices in the United States are based on the nominal cost of capital and a depreciated original cost rate base (RAV) that is not adjusted for inflation.

\subsubsection{Service Quality Incentives for Electric Distribution Companies in the United Kingdom and the United States ${ }^{13}$}

Any incentive regulation mechanism that provides incentives only for cost reduction also potentially creates incentives to reduce service quality when service quality and costs are positively related to one another. The regulatory mechanisms developed for electric distribution companies in the United Kingdom have long included an additional set of incentive mechanisms to provide incentives for the regulated firms to maintain or enhance service quality. Adding quality-related incentives to cost-control incentives makes

13. The United Kingdom has also applied incentive arrangements for distribution system losses that I will not discuss here. 
good sense in theory and in practice. However, integrating these incentive mechanisms into a package that gives the correct incentives on all relevant margins remains a considerable challenge for incentive regulation in practice.

By its 2004 review, OFGEM had developed several incentive mechanisms targeted at various dimensions of performance. These include: (a) two distribution service interruption incentive mechanisms targeted at the number of outages and the number of minutes per outage; (b) storm interruption payment obligations targeted at distribution company response times to outages caused by severe weather events; (c) quality of telephone responses during both ordinary weather conditions and storm conditions; and (d) a discretionary award based on surveys of customer satisfaction. Overall, about 4 percent of total revenue on the downside and an unlimited fraction of total revenue on the upside are subject to these quality of service incentive mechanisms (see table 5.5). Is this the right allocation of financial risk to variations in service quality? Nobody really knows.

OFGEM uses statistical and engineering benchmarking studies and forecasts of planned maintenance outages to develop targets for the number of customer outages and the average number of minutes per outage for each distribution company. The individual distribution companies are disaggregated into different types (e.g., voltages) of distribution circuits, and performance benchmarks and targets are developed for each based on comparative historical experience and engineering norms. Aggregate performance targets for each distribution company are then defined by reaggregating the targets for each type of circuit (OFGEM 2004a) appendix to June 2004 proposals) to match up circuits that make up each electric distribution company. Both planned (maintenance) and unplanned outages are taken into account to develop the outage targets. The targets incorporate performance improvements over time and reflect, in part, customer surveys of the value of improved service quality. There is a fairly wide range in the targets among the fourteen distribution companies in the United Kingdom, reflecting dif-

\section{Table 5.5}

Revenue exposure to quality of service variations

\begin{tabular}{lll}
\hline Incentive arrangement & \multicolumn{1}{c}{ Current } & \multicolumn{1}{c}{ Proposal } \\
\hline Interruption incentive scheme & $+2 \%$ to $-1.75 \%$ & $+/-3 \%$ \\
Storm compensation arrangements & $-1 \%$ & $-2 \%$ \\
Other standards of performance & Uncapped & Uncapped \\
Quality of telephone response & $+/-0.125 \%$ & $+0.05 \%$ to $-0.25 \%$ \\
Quality of telephone response in & Not applicable & 0 initially \\
$\quad$ storm conditions & Not applicable & $+/-0.25 \%$ for 3 yrs \\
Discretionary reward scheme & $+2 \%$ to $-2.875 \%$ & $4 \%$ to $+£ 1 \mathrm{~m}$ downside \\
Overall cap/total & & No overall cap on upside \\
\end{tabular}

Source: OFGEM (2004d, 16). 
Table 5.6

Targets for average number of customer interruptions by distribution company and year

\begin{tabular}{lrrrrrrrrr}
\hline & \multicolumn{3}{c}{ Actual } & & \multicolumn{5}{c}{ Target } \\
\cline { 2 - 3 } & $2001 / 2$ & $2002 / 3$ & $2003 / 4$ & & $2005 / 6$ & $2006 / 7$ & $2007 / 8$ & $2008 / 9$ & $2009 / 10$ \\
\hline CN-Midlands & 120.1 & 99.8 & 113.1 & & 109.4 & 107.8 & 106.2 & 104.6 & 103.0 \\
CN-East Midlands & 77.0 & 74.7 & 83.4 & & 77.9 & 77.5 & 77.1 & 76.7 & 76.3 \\
United Utilities & 55.5 & 65.7 & 50.3 & & 57.2 & 57.1 & 57.1 & 57.1 & 57.1 \\
CE-NEDL & 82.2 & 76.5 & 64.9 & & 74.5 & 74.5 & 74.5 & 74.5 & 74.5 \\
CE-YEDL & 77.4 & 62.8 & 66.0 & & 68.7 & 68.6 & 68.5 & 68.5 & 68.4 \\
WPD-South West & 100.7 & 81.8 & 71.0 & & 84.5 & 84.5 & 84.5 & 84.5 & 84.5 \\
WPD-South Wales & 112.7 & 96.0 & 94.7 & & 99.7 & 98.2 & 96.8 & 95.3 & 93.9 \\
EDF-LPN & 38.0 & 35.8 & 34.7 & & 36.2 & 36.2 & 36.2 & 36.2 & 36.2 \\
EDF-SPN & 93.0 & 88.4 & 96.1 & & 90.5 & 88.5 & 86.5 & 84.5 & 82.5 \\
EDF-EPN & 101.0 & 84.7 & 89.6 & & 90.3 & 88.8 & 87.2 & 85.7 & 84.2 \\
SP Distribution & 59.0 & 63.4 & 60.2 & & 60.9 & 60.8 & 60.8 & 60.8 & 60.8 \\
SP Manweb & 46.1 & 41.0 & 49.2 & & 46.7 & 46.7 & 46.7 & 46.7 & 46.7 \\
SSE-Hydro & 115.4 & 90.0 & 84.1 & & 96.2 & 95.8 & 95.5 & 95.2 & 94.9 \\
SSE-Southern & 98.3 & 91.5 & 86.1 & & 91.0 & 90.1 & 89.2 & 88.3 & 87.4 \\
Average & 83.1 & 75.0 & 75.3 & & 77.1 & 76.5 & 75.8 & 75.1 & 74.5 \\
\hline
\end{tabular}

Source: OFGEM (2004d, 17).

ferences in the configurations of the networks. OFGEM also has added cost allowances into the price control $\left(p_{o}\right)$ to reflect estimates of the costs of improving service quality in these dimensions. See table 5.6 as an example.

Once the performance targets are set, a financial penalty/reward structure needs to be applied to it to transform the physical targets into financial penalties and rewards. The natural approach would be to apply estimates of the value of outages and outage minutes to customers (OFGEM surveys indicated customers valued reducing the number of minutes per outage more than the number of outages) to define prices for outages and outage duration. OFGEM did not take this approach in the most recent distribution company price review. Instead it developed prices for outages and outage duration by taking the target revenue at risk and dividing it by a performance band around the target ( 25 percent and 30 percent, respectively). This approach seems rather arbitrary and yields a fairly wide variation in the effective price per outage and the price per minute of outage across distribution companies. See tables 5.7 and 5.8 as examples. OFGEM's 2004 review included a storm restoration compensation incentive mechanism. The distribution companies are given incentives to restore service within a specified time period and if they do not they must pay compensation to customers as defined in the incentive mechanism. The mechanism includes adjustments for exceptional events. Under normal weather conditions customers 


\begin{tabular}{|c|c|c|c|c|c|c|}
\hline DNO & $2005 / 6$ & $2006 / 7$ & $2007 / 8$ & $2008 / 9$ & $2009 / 10$ & $\begin{array}{c}2004 / 5 \text { IIP } \\
\text { incentive rate }\end{array}$ \\
\hline CN-Midlands & 0.10 & 0.11 & 0.11 & 0.11 & 0.11 & 0.06 \\
\hline CN-East Midlands & 0.15 & 0.15 & 0.15 & 0.15 & 0.16 & 0.09 \\
\hline United Utilities & 0.18 & 0.18 & 0.18 & 0.19 & 0.19 & 0.13 \\
\hline CE-NEDL & 0.10 & 0.10 & 0.10 & 0.10 & 0.10 & 0.06 \\
\hline CE-YEDL & 0.13 & 0.14 & 0.14 & 0.14 & 0.14 & 0.08 \\
\hline WPD-South West & 0.10 & 0.10 & 0.10 & 0.10 & 0.11 & 0.07 \\
\hline WPD-South Wales & 0.07 & 0.07 & 0.07 & 0.08 & 0.08 & 0.03 \\
\hline EDF-LPN & 0.29 & 0.30 & 0.30 & 0.31 & 0.31 & 0.24 \\
\hline EDF-SPN & 0.09 & 0.09 & 0.09 & 0.10 & 0.10 & 0.05 \\
\hline EDF-EPN & 0.15 & 0.15 & 0.16 & 0.16 & 0.17 & 0.10 \\
\hline SP Distribution & 0.23 & 0.23 & 0.23 & 0.23 & 0.23 & 0.13 \\
\hline SP Manweb & 0.18 & 0.18 & 0.18 & 0.18 & 0.18 & 0.11 \\
\hline SSE-Hydro & 0.08 & 0.08 & 0.08 & 0.09 & 0.09 & 0.04 \\
\hline SSE-Southern & 0.18 & 0.18 & 0.18 & 0.19 & 0.19 & 0.11 \\
\hline Average & $0.15 \mathrm{z}$ & 0.15 & 0.15 & 0.15 & 0.15 & 0.10 \\
\hline
\end{tabular}

Source: OFGEM (2004d, 19).

Notes: IIP = International Incentive Program. Incentive rates for the number of customers interrupted per 100 customers ( $£ \mathrm{~m} / \mathrm{CI}-02 / 03$ prices $)$.

Table 5.8 Incentive payments for minutes lost by distribution company and year

\begin{tabular}{lcccccc}
\hline DNO & & & & & & $\begin{array}{c}2004 / 5 \text { IIP } \\
\text { incentive rate }\end{array}$ \\
\hline CN-Midlands & 0.14 & 0.15 & 0.15 & 0.16 & 0.17 & 0.10 \\
CN-East Midlands & 0.18 & 0.19 & 0.20 & 0.21 & 0.23 & 0.17 \\
United Utilities & 0.22 & 0.23 & 0.23 & 0.24 & 0.25 & 0.16 \\
CE-NEDL & 0.13 & 0.13 & 0.14 & 0.14 & 0.14 & 0.08 \\
CE-YEDL & 0.17 & 0.18 & 0.18 & 0.19 & 0.20 & 0.16 \\
WPD-South West & 0.17 & 0.17 & 0.17 & 0.18 & 0.18 & 0.13 \\
WPD-South Wales & 0.12 & 0.12 & 0.12 & 0.12 & 0.13 & 0.05 \\
EDF-LPN & 0.33 & 0.33 & 0.34 & 0.35 & 0.35 & 0.25 \\
EDF-SPN & 0.12 & 0.13 & 0.14 & 0.15 & 0.16 & 0.09 \\
EDF-EPN & 0.23 & 0.24 & 0.25 & 0.25 & 0.26 & 0.17 \\
SP Distribution & 0.27 & 0.28 & 0.30 & 0.33 & 0.35 & 0.14 \\
SP Manweb & 0.20 & 0.21 & 0.22 & 0.23 & 0.24 & 0.12 \\
SSE-Hydro & 0.10 & 0.11 & 0.11 & 0.11 & 0.11 & 0.04 \\
SSE-Southern & 0.24 & 0.25 & 0.26 & 0.27 & 0.28 & 0.15 \\
Average & 0.19 & 0.19 & 0.20 & 0.21 & 0.22 & 0.13 \\
\hline
\end{tabular}

Source: OFGEM (2004f, 19).

Note: Incentive rates for the number of customer minutes lost per customer (£m/CML). 
are eligible to be paid $£ 50$ pounds for an interruption that lasts more than twenty-four hours ( $£ 100$ for nondomestic) and a further $£ 25$ for each subsequent twelve-hour period. It is not clear where the values for these payments come from. If a customer consumes $20 \mathrm{kWh}$ per day ( $600 \mathrm{kWh}$ per month) the implied value of lost load is $£ 2.5$ per lost $\mathrm{kWh}$, or roughly $\$ 5,000 / \mathrm{MWh}$ of lost energy. Alternative compensation arrangements are applied when there are severe weather conditions. Both the triggers and the compensation change. The trigger periods for compensation are defined below and the amount of compensation starts at $£ 25$ when the trigger is hit with a cap of $£ 200$ per customer.

Finally, there were penalties and rewards for the quality of telephone service, based on the results of customer surveys.

In its "RIIO" (Revenue = Incentives + Innovation + Outputs) model, introduced as part of OFGEM's RPI-X@20 project, the measurement of outputs that include a number of quality metrics was emphasized, and both quantitative and subjective incentives (including the potential license revocation) are tied to performance on these dimensions (OFGEM 2010).

\subsubsection{Electricity Transmission: Regulation of the National Grid Company (NGC) in England and Wales}

The application of incentive regulation mechanisms to local electricity and gas distribution companies, water utilities, and local telephone companies is gaining acceptance around the world. However, these concepts have rarely been applied to the owners of electric transmission networks. The regulation of the National Grid Company (NGC) in England and Wales is one of the few examples. ${ }^{14}$ The regulatory mechanisms used to regulate NGC are conceptually similar to those used to regulate the UK distribution companies. And, as with the UK distribution companies, the regulatory mechanisms have evolved over time as experience has been gained with them and with NGC's performance in response to them. The discussion in this section focuses on the mechanisms in place as of the 2004 review.

When the electricity sector was privatized and restructured in England and Wales in 1990, a separate transmission company - NGC - was created to own, maintain, operate, and invest in the England and Wales transmission network. It was originally owned by the distribution companies but was spun off as an independent company in 1995. NGC is subject to regulation by OFGEM. Separate but compatible incentive regulation mechanisms are applied to the transmission owner (TO) and system operating functions (SO). These regulatory mechanisms effectively yield values for the target revenues NGC is permitted to earn from charges made to generators, electricity suppliers, and distribution companies for transmission service and system operations. These mechanisms define the aggregate revenues that

14. Argentina has also applied incentives of various kinds to the owners of the high voltage transmission networks in the country (Pollitt 2004). 
NGC is allowed to earn in each period - the incentive mechanism defines the average price level for transmission service.

The allowed aggregate revenues determined through the regulatory process are then recovered through a set of prices for the services provided by NGC. Transmission customers (generators and retail suppliers) pay NGC for the aggregate operating and capital costs allowed for the transmission network, defined by the basic incentive mechanism pursuant to a regulated tariff. ${ }^{15}$ The tariff has two basic components. The first is a "shallow" connection charge that allows NGC to recover the capital (depreciation, return on investment, taxes, etc.) and operating costs associated with the facilities that support each specific interconnection (now using the "Plugs" methodology). The second component of the transmission tariff is composed of the Transmission Network Use of System Charges (TNUoS) (NGC 2004a, 2004b, 2004c). The SO revenues defined by the SO incentive mechanism are then recovered as surcharges on the price of energy delivered to each transmission customer, reflecting variations in these charges at different points in time.

Thus, the general level of charges is set to allow NGC to recover its costof-service based "revenue requirement" or "allowed revenues" as adjusted through the incentive regulation mechanism that I will discuss presently. The structure of the TNUoS charges provides for price variation by location on the network based upon (scaled) differences in the incremental costs of injecting or receiving electricity at different locations, as specified in the Investment Cost Related Pricing Methodology. The regulator determines the structure of the charges whose level is adjusted each year to yield NGC's allowed aggregate revenues. The objective of this pricing mechanism is described as follows:

[E]fficient economic signals are provided to Users when services are priced to reflect the incremental costs of supplying them. Therefore charges should reflect the impact that Users of the transmission system at different locations would have on National Grid's costs, if they are to increase or decrease their use of the system. These costs are primarily defined as the investment costs in the transmission system, maintenance of the transmission system and maintaining a system capable of providing a secure bulk supply of energy. (NGC 2004a, 2004b, 2004c).

So, for example, generators pay significantly higher transmission service costs in the North of England than in the South (where the prices may be negative) because there is congestion from North to South and "deep" transmission network reinforcements are more likely to be required to accommodate new generation added at various locations in the North but not in the South. ${ }^{16}$ Similarly, load in the South pays more than load in the North

15. http://www.nationalgrid.com/uk/, click on "charging."

16. "Deep" transmission network reinforcements refer to reinforcements of the core network that serves large groups of generators and demand points as opposed to facilities that connect a single generator or small group of generators to the core network. 
because transmission enhancements to increase capacity from constrained generation export areas benefits customers in the South more than those in the North.

Unlike the assumption reflected in some of the theoretical work on price cap regulation, NGC is not free to adjust the price structure independently. Indeed, this freedom is rarely given to electric transmission and distribution companies subject to price cap regulation. Accordingly, as with the distribution companies in the United Kingdom, price caps are used primarily as mechanisms to provide incentives for cost reduction by giving the regulated firm a budget constraint that (for some time period) is exogenous, not to give the firm the freedom to set the optimal price structure.

Finally, in its role as SO, NGC has an obligation to balance the supply and demand for energy in the system in real time (energy balancing) and to meet operating reliability criteria (system balancing). These costs include the net costs NGC incurs to buy and sell power in the balancing market (or through short-term bilateral forward contracts), to balance supply and demand at each location, including to manage congestion, provide ancillary services, and other actions it must take to meet the network's operating reliability standards, and system losses. These costs are recovered from system users through an "uplift" charge based (mediated through an incentive regulatory mechanism discussed further below) on the quantities of energy supplied to or taken from the network at various points in time.

The regulatory framework for determining the revenues that NGC can recover through the use of system charges and the energy and system balancing charges is based on a set of incentive regulation mechanisms that have evolved over time.

As of the 2004 review, the primary mechanism covering NGC's TO costs and charges was a price cap developed using methods that are similar to those used for the UK electric distribution companies. This mechanism has a cost-of-service base, a performance-based incentive, and a ratchet that resets prices from time to time to reflect NGC's realized or forecast costs. A base annual aggregate "allowed revenue" for use of system charges is established at the beginning of each five-year "price review" period (though the latest period is being extended to seven years by mutual agreement on NGC and the regulator) in much the same way as for the distribution companies discussed earlier. As for the distribution companies, the accounting for operating costs and capital costs are different. For capital costs a rate base (regulatory assets value or RAV) is defined that is composed of the depreciated original cost of existing assets that make up the transmission system inflated to reflect inflation since the assets were installed. The forecast cost of incremental capital expenditures budgeted for the next five years to meet NGC's interconnection and system security criteria are added to the RAV. The final capital investment budget is determined by OFGEM through a public consultation process and reports by experts retained by OFGEM. Deprecia- 
tion rates are then applied to the RAV each year to develop a depreciation component of the user charge for capital and deducted from the RAV. A real cost of debt and equity capital and a debt/equity ratio are defined and applied to the RAV to yield the allowed rate-of-return component of capital charges for each year of the price control period. The values for allowable O\&M (operation and maintenance) expenditures during the future price control period are defined and added to each year's capital charges (depreciation, allowed rate-of-return on investment, and capital related taxes). A target rate of productivity improvement in operating costs - the $x$ factor-is included in the forecast of allowable real operating costs, or alternatively, the year one allowed operating costs are adjusted by the $x$ factor chosen by OFGEM, in addition to the RPI inflation adjustment over time.

Statistical benchmarking is very difficult for transmission networks. There is only one transmission network in England and Wales. The composition of a particular transmission network depends on many variables, including the distribution of generators and load, population density, geographic topography, the attributes and age of the legacy network's components and various environmental constraints affecting siting of new lines, transformers, and substations. Comparable cost and performance data are also not collected across transmission networks. Indeed, there is no standardization of where the transmission network ends and the distribution network begins. In the United Kingdom, the transmission network includes network elements that operate at $270 \mathrm{kv}$ and above. In the United States and France transmission includes network elements that operate down to $60 \mathrm{kv}$ or lower. Thus, "transmission" includes different types of facilities with different costs and different performance attributes in these two sets of countries. Benchmarking one against the other would not be very meaningful. In the United States there is no systematic collection of data on transmission network performance measures (US Energy Information Administration 2004). Accordingly, opportunities for relying on statistical benchmarking are not yet available in the United States because the necessary data are not collected and the value of $x$ is determined through a regulatory consultation process rather than through statistical benchmarking studies based on NGCs forecasts of O\&M requirements, wage escalation, and various engineering studies of the physical needs of the network and the costs of alternative methods to respond to them performed for OFGEM by independent consultants. Transmission service customers participate in this consultation process as well. (I suppose that the phrase "consultation process" sounds better than "rate case," but they are effectively the same animals.)

The allowed operating and capital cost values are expressed at the price levels prevailing at the time the price review is complete and then are escalated automatically during the price control period according to the RPI. Unbudgeted capital expenditures during the price review period can be considered in the next price review, though NGC may be at risk for amortization 
charges during the period between reviews. Underspending on capital may also be considered in the next price review and adjustments made going forward. After a five-year (or longer) period another price review is commenced, the starting price is reset to reflect then-prevailing costs, and new adjustment parameters are defined for the next review period. ${ }^{17}$

As outlined earlier, in its role as the $\mathrm{E} \& \mathrm{~W}$ (England and Wales) system operator (SO), ${ }^{18} \mathrm{NGC}$ is also subject to a separate set of incentive regulation mechanisms. Unlike the price cap mechanism used to regulate the level of TO charges, the SO incentive mechanism was adjusted each year. Each year forward targets were established for the costs of system balancing services and system losses (OFGEM 2005). Until the 2004 SO incentive review, a sharing or sliding scale formula was specified, which places NGC at risk for a fraction (e.g., 30 percent) of deviations from this benchmark (up or down) with caps on profits and losses. There was also a cap and a floor. Table 5.9 displays the attributes of the SO incentive mechanisms in effect from 2001 to 2005 after the New Electricity Trading Arrangements (NETA) went into operation. ${ }^{19} \mathrm{~A}$ similar incentive regulation mechanism applied to the SO during the late 1990s when the previous wholesale power pool was in operation. The choice of the SO incentive mechanism is only the second example that I am aware of where the regulated firm was offered a menu of (three) incentive arrangements with different sharing fractions and different caps and floors. The three-option menu offered to NGC for 2005 to 2006 is displayed in table 5.10. NGC chose option 2 after some adjustments to the target values.

Until the early 2000s, there was no formal incentive mechanism that applied to system reliability - network failures that lead to administrative customer outages or "unsupplied energy." ${ }^{20}$ In response to the London blackout during the late summer of 2003, OFGEM developed and applied a new incentive regulation mechanism that applies to severe network outages that lead to customer outages and related "unsupplied energy" (OFGEM 2004f). NGC was assessed penalties or received rewards when outages fell outside of a "deadband" of $+/-5$ percent, defined by the distribution of historical outage experience (and with potential adjustments for extreme weather events), using a sliding scale with a cap and a floor on the rev-

17. There is also an incentive regulation mechanism that governs network losses that involves annual adjustments in the benchmark.

18. Recently expanded to include Scotland.

19. In the most recent $\mathrm{SO}$ incentive review, the parties could not agree on an incentive mechanism and SO compensation revered to cost of service, the default option. This suggests that the regulator failed to understand the true distribution of costs and/or to properly reflect it in the menu.

20. Transmission networks have quite a bit of redundancy built into them. When specific pieces of equipment fail, electricity is naturally rerouted over the rest of the network, and there are no customer outages that result. However, multiple transmission network equipment failures can lead to customer outages, though customer outages are most frequently the result of distribution network equipment failures. 
Table 5.9

Transmission system operator incentive parameters

\begin{tabular}{lllll}
\hline Parameter & 2001/2 scheme & 2002/3 scheme & 2003/4 scheme & 2004/5 scheme \\
\hline Target & $£ 484.6$ million to & $£ 460$ million & $£ 416$ million & $£ 4415$ million \\
& $£ 514.4$ million & & & \\
Upside sharing factor & $40 \%$ & $60 \%$ & $50 \%$ & $40 \%$ \\
Downside sharing factor & $12 \%$ & $50 \%$ & $50 \%$ & $40 \%$ \\
Cap & $£ 46.3$ million & $£ 60$ million & $£ 40$ million & $£ 40$ million \\
Floor & $-£ 15.4$ million & $-£ 45$ million & $-£ 40$ million & $-£ 40$ million \\
\hline
\end{tabular}

Source: OFGEM $(2005,95)$.

Table 5.10

Menu of SO incentive contracts for 2005-2006

\begin{tabular}{llll}
\hline Proposed value & Option 1 & Option 2 & Option 3 \\
\hline Target & $£ 480$ million & $£ 500$ million & $£ 515$ million \\
Upside sharing factor & $60 \%$ & $40 \%$ & $25 \%$ \\
Downside sharing factor & $15 \%$ & $20 \%$ & $25 \%$ \\
Cap & $£ 50$ million & $£ 40$ million & $£ 25$ million \\
Floor & $-£ 10$ million & $-£ 20$ million & $-£ 25$ million \\
\hline
\end{tabular}

Source: OFGEM (2005, summary, page 3).

Notes: OFGEM also outlined a potential revision to the treatment of transmission losses within the SO incentive scheme, which entailed a move from a gross to a net transmission losses scheme. OFGEM considered that the introduction of a net transmission losses scheme should be considered, as it better reflects the true balancing costs to which the market is exposed.

enue impact. The incentive structure is consistent with a value of unsupplied energy of $£ 33,000 / \mathrm{MWh}$, though OFGEM indicated that it did not derive the incentive structure from an estimate of the value of lost energy, but rather to stimulate managerial attention in what was designed to be an interim incentive mechanism (OFGEM 2004f, 8, 20). OFGEM argued that it is very difficult to come up with accurate measures of the value of lost energy. Nor does the mechanism provide for compensation to customers affected by outages that trigger penalties for the SO (or charges for rewards) (OFGEM 2004f, 20). The implicit value of unsupplied energy reflected in the transmission network incentive mechanism is about an order of magnitude higher that the value reflected in the comparable distribution network mechanisms.

\subsubsection{Reflections on Price-Cap Regulation versus Cost-of-Service Regulation in Practice}

The basic price cap regulatory mechanism used to regulate electricity, gas, and water distribution and transmission companies in the United Kingdom is often contrasted with characterizations of cost-of-service or "cost plus" regulation that developed in the United States during the twentieth century. However, I believe that there has been less difference than may first meet the 
eye. The UK's implementation of a price cap based regulatory framework is best characterized as a combination of cost-of-service regulation, the application of a high-powered incentive scheme for operating costs for a fixed period of time, followed by a cost-contingent price ratchet to establish a new starting value for prices. The inter-review period is similar to "regulatory lag" in the US context (Joskow 1972, 1974; Joskow and Schmalensee 1986), except it is structured around a specific RPI-X formula that employs forward-looking productivity assessments, allows for automatic adjustments for inflation, and has a fixed duration. A considerable amount of regulatory judgment is still required by OFGEM. The regulator must agree to an appropriate level of the starting value for "allowable" O\&M as well as a reasonable target for improvements in O\&M productivity during the inter-review period. The regulator must also review and approve investment plans ex ante and make judgments about their reasonableness ex post, though investment programs that fall within budgeted values are unlikely to be subject to ex post review. It does this without statistical benchmarking studies, which are unavailable. An allowed rate of return must be determined as well as compatible valuations of the rate base (capital stock) and depreciation rates. Cost accounting and cost reporting protocols are required to implement sound incentive regulation mechanisms.

Thus, there are many similarities here with the way cost-of-service regulation works in practice in the United States. Indeed, perhaps the greatest difference is philosophical. OFGEM takes a view that recognizes that by providing performance-based incentives for regulated utilities to reduce costs, it can yield consumer benefits in the long run by making it profitable for the firm to make efficiency improvements. If the firm overperforms against the target, consumers eventually benefit at the next price review. It has generally (though not always) been willing to allow the regulated firms to earn significantly higher returns than their cost of capital when these returns are achieved from cost savings beyond the benchmark, knowing that the next "ratchet" will convey these benefits to consumers. ${ }^{21}$ Under traditional US regulation, the provision of incentives through regulatory lag is more a consequence of the impracticality of frequent price reviews and changing economic conditions than by design.

\subsection{Performance of Incentive Regulation Mechanisms for Electric Distribution and Transmission Network}

There has been relatively little systematic analysis of the effects of the application of incentive regulation mechanisms on the performance of elec-

21. There is at least one problem with the fixed ratchet period. A dollar (or pound sterling) of cost savings in year one is worth much more to the firm than a dollar of cost savings in year five. OFGEM recently adopted policies to equalize the returns from cost saving during the inter-review period. 
tric distribution and transmission companies. ${ }^{22}$ Privatization, restructuring, and the application of high-powered regulatory mechanisms has led to improvements in labor productivity and service quality in electric distribution systems in England and Wales, Argentina, Chile, Brazil, Peru, New Zealand, and other countries (Newbery and Pollitt 1997; Rudnick and Zolezzi 2001; Bacon and Besant-Jones 2001; Estache and Rodriguez-Pardina 1998; Pollitt 2008). Sectors that had experienced physical distribution losses due to poor maintenance and antiquated equipment, as well as resulting from thefts of electric service, have generally experienced significant reductions in both types of losses. Penetration rates for the availability of electricity to the population have increased in those countries where service was not already universally available and queues for connections have been shortened. Distribution and transmission network outages have declined. Improved performance of regulated distribution (and sometimes transmission) systems has accompanied privatization and the application of high-powered PBR mechanisms almost everywhere it has been implemented. Most of these studies have focused on developing countries where the prereform levels of performance were especially poor. Moreover, it is difficult to disentangle the effects of privatization, restructuring, and incentive regulation from one another.

One of the most comprehensive studies of the postreform performance of the regional electricity distribution companies in the United Kingdom (distribution and supply functions) was done by Domah and Pollitt (2001). They find significant overall increases in productivity over the period 1990 to 2000 and lower real "controllable" distribution costs compared to a number of benchmarks. However, controllable costs and overall prices first rose in the early years of the reforms before falling dramatically after 1995. The first application of price cap mechanisms to the RECs in 1990 was too generous (average of RPI +2.5 percent) and a lot of rent was left on the table for the REC's initial owners (who cleverly soon sold out to foreign buyers). Subsequent price cap mechanisms placed much more cost pressure on the RECs and stimulated large increases in realized productivity and falling distribution charges.

Bertram and Twaddle (2005) provide an interesting analysis of the combined effects on the prices charged for distribution service resulting from capital asset valuation decisions and the impacts of price cap-type regulation on the operating costs of distribution networks. When sector restructuring takes place, one decision that must be made is how to value the assets of the distribution and transmission companies that will be used for regulatory purposes going forward; that is, how the rate base or RAV of the

22. There is a much more extensive body of empirical work that examines the effects of incentive regulation mechanisms, primarily price caps, on the performance of telecommunications firms. For example, Ai and Sappington 2002; Sappington 2003; and Ai, Martinez, and Sappington 2004. 
capital stock will be valued. The typical approach has been to carry forward the existing depreciated book value of historical investments in transmission and distribution into the new liberalized regime so that the base level of distribution and transmission charges associated with the recovery of capital-related charges does not change as a consequence of the transition. Incremental investments are then accounted for more or less as they were under the old regime (as in the United States and Canada) or economic/ inflation accounting methods and approximations to economic depreciation applied to incremental investments (as in the United Kingdom). These decisions are further complicated in countries where the industry was state owned and did not employ rigorous capital cost accounting protocols or where prices were kept so low as to not even cover the carrying charges on plant and equipment.

Bertram and Twaddle (2005) review the impact of decisions made in New Zealand to "write up" the value of distribution company assets to reflect their "true" economic value (something like depreciated replacement cost new) as a component of the restructuring program. These asset values were then used to set the price levels within a price cap regulatory framework. The argument for doing so was that this would allow prices to rise to their efficient level and provide consumers with appropriate price signals. The arguments against this revaluation were that (a) it would lead to significant price increases, (b) nonlinear pricing could be used to restore the correct price incentives on the margin, and (c) it created windfall profits for distribution network owners and undermined support for restructuring and competition.

Bertram and Twaddle focus on the effects of this asset revaluation program on distribution service price and profit levels in New Zealand. Prices and price-operating cost margins rose significantly. However, their work also demonstrates that operating costs incurred by distribution companies in New Zealand fell very significantly during the same period of time. These cost savings appear to reflect both the consolidation of many small distribution companies through mergers and the incentives for cost reduction provided by a high-powered incentive scheme (see figure 5.2).

Distribution service quality, at least as measured by supply interruptions per 100 customers and average minutes of service lost per customer, has also improved in the United Kingdom since the restructuring and privatization initiative in 1990 (OFGEM 2003a, 21). This suggests that incentive regulation has not led, as some had feared, to a degradation in these dimensions of service quality.

Let me conclude with a few observations on the performance of the incentive regulation mechanisms that were applied to NGC by OFGEM during its first decade. When the new $\mathrm{E} \& \mathrm{~W}$ industry structure and market arrangements were implemented in 1990, the system naturally started with a legacy network and configuration of generating capacity. Substantial entry of new 


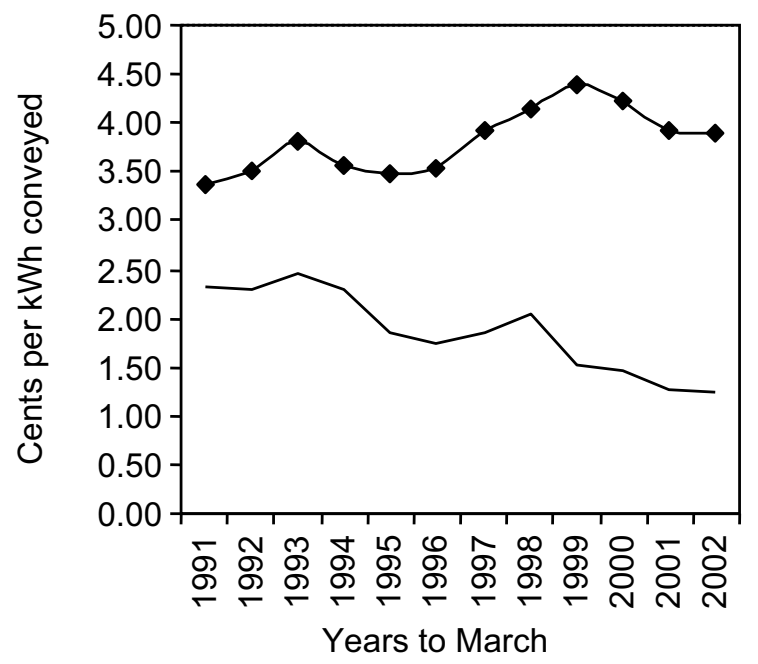

$\multimap$ Average revenue — Average operating costs

Fig. 5.2 Distribution network prices and costs in New Zealand

Source: Bertram and Twaddle (2005).

generating capacity and retirements of old generating capacity followed, with major changes in power flows over the legacy network. During the initial years of operation there was no incentive regulation mechanism governing system operating costs, including the costs of managing congestion and other network constraints. NGC's SO costs escalated rapidly, growing from about $\$ 75$ million per year in 1990/91 to almost $\$ 400$ million per year in 1993/94. After the introduction of the SO incentive scheme in 1994, these costs fell to about $\$ 25$ million in 1999/2000. OFGEM estimates that NGC's system operating costs fell by about $£ 400$ million between 1994 and 2001 (OFGEM, April 2004). Overall costs of transmission service, including operating, system balancing (which includes congestion costs), use of system, and connection charges fell by about 50 percent between 1994 and 2001. NGC's loss rate has also declined over time. A new SO incentive scheme was introduced when NETA went into operation in early 2001. NGC's SO costs fell by nearly 20 percent over the three-year period since the new scheme was introduced (OFGEM, December 2003).

The organizational and regulatory arrangements that characterize the system in England and Wales are generally viewed to have been quite successful in supporting competitive wholesale and retail power markets with a transmission system that has attractive operating and investment results. During the period, demand grew, about 25,000 MW of new generating capacity entered the system, and almost an equal amount was retired (UK Depart- 
ment of Trade and Industry 2002). Power flows changed significantly on the network. While network investment is cyclical, following cycles of generation additions and retirements, intracontrol area investment postrestructuring has increased significantly compared to intracontrol area investment pre-restructuring, while congestion costs have declined significantly since 1994. Network losses have declined and system reliability has been maintained. A more formal assessment of performance is difficult because it is very challenging to define a counterfactual for comparison purposes.

\subsection{Discussion}

During the last two decades, the theoretical foundations for incentive regulation of legal monopolies have developed considerably, and now provide a reasonably mature theoretical framework for designing incentive regulatory mechanisms for practical application. However, the application of these concepts to electric distribution and transmission networks has lagged considerably behind these theoretical developments for a variety of reasons. Incentive regulation in practice is considerably more complicated than incentive regulation in theory. I offer the following observations about the relationship between theory and practice.

Incentive regulation has been promoted as a straightforward and superior alternative to traditional cost-of-service or rate-of-return regulation. In practice, incentive regulation is more a complement to than a substitute for traditional approaches to regulating legal monopolies. In some ways it is more challenging. Whether the extra effort is worth it depends on whether the performance improvements justify the additional effort. Incentive regulation in practice requires a good accounting system for capital and operating costs, cost reporting protocols, data collection, and reporting requirements for dimensions of performance other than costs. Capital cost accounting rules are necessary, a rate base for capital must still be defined, depreciation rates specified, and an allowed rate of return on capital determined. Comprehensive "rate cases" or "price reviews" are still required to implement "simple" price cap mechanisms. Planning processes for determining needed capital additions are an important part of the process of setting total allowed revenues going forward. Performance benchmarks must be defined and the power of the relevant incentive mechanisms determined. The information burden to implement incentive regulation mechanisms well is similar to that for traditional cost-of-service regulation.

What distinguishes incentive regulation in practice from traditional costof-service regulation is that this information is used more effectively, looking forward rather than backward, and recognizing that regulators have imperfect and asymmetric information that makes the use of regulatory mechanisms that clearly recognize the associated adverse selection and moral hazard problems and are designed to mitigate them. The proof of 
the pudding must ultimately lie in analyses of the performance of alternative regulatory mechanisms. More work needs to be done on the analysis of the performance of incentive regulation mechanisms applied to electric distribution and transmission system.

Incentive regulation in practice is clearly an evolutionary process. One set of mechanisms is tried, their performance assessed, additional data and reporting needs to be identified, and refined mechanisms developed and applied. This type of evolutionary process seems to me to be inevitable. However, to the extent that changes in regulatory mechanisms are contingent on past performance, this kind of evolutionary process raises credibility issues and may lead to strategic behavior of firms that are playing a repeated game with their regulators. Theoretical work that more accurately captures these adaptation properties of incentive regulation in practice would be desirable.

Price cap mechanisms are the most popular form of incentive regulation used around the world, in part because this mechanism has been heavily advertised as being a simple alternative to cost-of-service regulation. There is a lot of loose and misleading talk about the application of price caps in practice. From a theoretical perspective the infatuation with price caps as incentive devices is surprising since price caps are almost never the optimal solution to the trade-off between efficiency and rent extraction when the regulator must respect the regulated firm's budget-balance constraint (Schmalensee 1989b) and raise service quality issues. However, price caps in practice are not like "forever" price caps in theory. There are ratchets every few years that reduce the power of the incentive scheme and make it easier to deal with excessive or inadequate rents left to the firm. They are not so simple to implement because defining the relevant capital and operating costs and associated benchmarks is challenging (see also ACCC 2012). Price caps are also typically (eventually) accompanied by other incentive mechanisms to respond to concerns about service quality. Evaluating the performance of price cap mechanisms without taking account of the entire portfolio of incentive mechanisms in place can lead to misleading results. Effective implementation of a good price cap mechanism with periodic ratchets requires many of the same types of accounting, auditing, capital service, and cost of capital measurement protocols as does cost-of-service regulation. Capital cost accounting and investment issues have received embarrassingly little attention in both the theoretical literature and applied work on price caps and related incentive mechanisms, especially the work related to benchmarking applied to the construction of price cap mechanisms. Proceeding with price caps without this regulatory information infrastructure and an understanding of benchmarking and the treatment of capital costs, as has been the case in many developing countries following guidance from World Bank regulatory gurus, can lead to serious performance problems.

In practical applications to electric distribution and transmission net- 
works there is an implicit assumption that there is a dichotomy between incentives contracts (aggregate revenue targets) and price setting (price structures). This dichotomy between the firm's budget or allowed revenues and its price structure is consistent with the historical development of regulatory practice in the United States where rate cases separate the determination of allowed revenues or revenue requirements from the specification of price structures that yield the indicated revenues (Joskow 1972; Joskow and Schmalensee 1986). A similar dichotomy has been adopted in the regulatory process in the United Kingdom. Regulated firms are given little flexibility to adjust price structures under the price cap mechanism. Accordingly, the primary role of price caps is to provide incentives for cost reduction, not to provide firms with the incentive to set optimal second-best prices given their overall budget constraints. The evaluations of the performance of price cap regulation should therefore be evaluated from the perspective of the effects on performance incentives, not on its effects on price structures since these are typically not chosen voluntarily by the regulated firm but are subject to independent regulatory determinations.

Incentive regulation theory implies that the adverse selection and moral hazard problems resulting from the regulators' information disadvantages are best handled by offering firms a mеnu of cost-contingent incentive contracts. Formal offers of menus are rare, though the give and take of regulatory negotiations may be a substitute. OFGEM's use of a menu of sliding scale schemes to deal with differences over capital investment forecasts for electric distribution companies seems to me to be an especially effective approach and, indeed, led the regulated firms to make more "reasonable" investment proposals, at least according to OFGEM. More frequent use of menus of incentive contracts in this way could improve incentive regulation in practice.

Collection of data on all relevant and significant measures of firm performance and the use of these data for benchmarking purposes and for developing performance targets is an important component of good incentive regulation in practice. To implement incentive regulation, regulators need the authority to require firms to collect performance data, to audit performance data, and to analyze these data. Absent these authorities and resources, incentive regulation mechanisms will not achieve their promise in practice.

As incentive regulation has evolved in the United Kingdom and other countries, the portfolio of incentive mechanisms that is being utilized has grown. While the initial focus was on reducing operating costs, it has now shifted to investment and various dimensions of service quality. Ideally these mechanisms should be fully integrated and differences in the power of the individual incentive schemes carefully considered. As things stand now there appear to be differences in the power of the incentives schemes as they relate to capital and operating costs. These problems are exacerbated in the United 
Kingdom and many other countries new to formal regulation by the lack of uniform systems of accounts and reporting requirements. Quality of service schemes appear to have been bolted onto schemes designed to provide incentives for cost reduction and do not effectively incorporate information on consumer valuations of quality and the costs of varying quality in different dimensions. While the value of lost or unsupplied energy is uncertain, it is better to use an imperfect estimate of the right number than a very specific estimate of the wrong number. Efforts need to be made to harmonize these schemes and to guard against distortions caused by differences in the effective power of the constituent components of the overall incentive mechanisms.

Incentive regulation mechanisms often have "deadbands," caps, and floors that place limits on the performance realizations for which the regulated firm is at risk. At first blush, the use of hard caps and floors on the realizations of sliding scale mechanisms that place kinks in the incentive structure are hard to rationalize from a theoretical perspective and appear to have poor incentive properties for realizations near to the kinks in the incentive contract. Caps and floors may be justified as reflecting outcomes that were not contemplated (bounded rationality) in the level and structure of the target performance norms and the distribution of profits around these targets. They effectively trigger renegotiation. However, it is likely that a multipart sliding scale structure that softens incentives as the cap and floor approaches would have superior efficiency properties. We need to better understand the popular use of hard caps and floors and try to better understand their efficiency properties.

Our ability to use incentive regulation mechanisms effectively is dependent on the attributes of the restructuring and liberalization program of which it is a part. For example, it is much easier to develop and apply an incentive regulation program to the electric transmission system in England and Wales because there is one integrated transmission owner and system operator. The balkanized ownership structure of transmission assets in the United States, combined with the separation of system operating functions (to nonprofit independent system operators) from transmission ownership, maintenance, physical operation, and investment, makes the application of incentive regulation mechanisms (indeed, any effective regulation mechanism) a very significant challenge. The difficulties are enhanced by the peculiar mix of federal and state regulation of transmission in the United States and the failure of the federal regulator to take an active role in defining performance attributes, collecting performance data, and developing performance norms. FERC Order 2000 effectively assigns these responsibilities to RTO/ISO entities, but they have not taken up this challenge to date (Joskow 2007).

It would be worthwhile to pursue more work on the performance of incentive regulation mechanisms on electric and gas distribution and transmis- 
sion companies in all relevant dimensions. The empirical research on the performance of incentive regulation in the telecommunications sector is much more extensive than is the research on electricity and gas networks. This kind of comparative institutional work is not easy, but it needs to be done, perhaps in conjunction with benchmarking studies that include firms subject to different types of regulation.

\section{References}

Ai, C., S. Martinez, and D. E. Sappington. 2004. "Incentive Regulation and Telecommunications Service Quality." Journal of Regulatory Economics 26 (3): $263-85$.

Ai, C., and D. Sappington. 2002. "The Impact of State Incentive Regulation on the US Telecommunications Industry." Journal of Regulatory Economics 22 (2): $133-59$.

Armstrong, M., S. Cowan, and J. Vickers. 1994. Regulatory Reform: Economic Analysis and British Experience. Cambridge, MA: MIT Press.

Armstrong, M., and D. M. Sappington. 2004. "Toward a Synthesis of Models of Regulatory Policy Design with Limited Information.” Journal of Regulatory Economics 26 (1): 5-21.

- 2007. "Recent Developments in the Theory of Regulation." In Handbook of Industrial Organization, vol. III, edited by M. Armstrong and R. Porter, 1557700. Amsterdam: Elsevier Science Publishers.

Armstrong, M., and J. Vickers. 1991. "Welfare Effects of Price Discrimination by a Regulated Monopolist.” Rand Journal of Economics 22:571-80.

Australian Competition and Consumer Commission (ACCC). 2012. "Regulatory Practices in Other Countries: Benchmarking Opex and Capex in Energy Networks." May.

Averch, H., and L. L. Johnson. 1962. "Behavior of the Firm under Regulatory Constraint." American Economic Review 52:1059-69.

Bacon, R. W., and J. E. Besant-Jones. 2001. "Global Electric Power Reform, Privatization and Liberalization of the Electric Power Industry in Developing Countries." Annual Reviews of Energy and the Environment 26:331-59.

Banerjee, A. 2003. "Does Incentive Regulation 'Cause' Degradation of Telephone Service Quality?" Information Economics and Policy 15:243-69.

Baron, D. 1989. "Design of Regulatory Mechanisms and Institutions.” In Handbook of Industrial Organization, vol. II, edited by R. Schmalensee and R. Willig, 1347447. Amsterdam: North Holland.

Baron, D., and D. Besanko. 1984. "Regulation, Asymmetric Information and Auditing." Rand Journal of Economics 15 (4): 447-70.

-1987a. "Commitment and Fairness in a Dynamic Regulatory Relationship." Review of Economic Studies 54 (3): 413-36.

1987b. "Monitoring, Moral Hazard, Asymmetric Information and Risk Sharing in Procurement Contracting." Rand Journal of Economics 18 (4): 509-32.

Baron, D., and R. Myerson. 1982. "Regulating a Monopolist with Unknown Costs." Econometrica 50 (4): 911-30.

Baumol, W., and A. K. Klevorick. 1970. "Input Choices and Rate of Return Regu- 
lation: An Overview of the Discussion." Bell Journal of Economics and Management Science 1 (2): 162-90.

Bertram, G., and D. Twaddle. 2005. "Price-Cost Margins and Profit Rates in New Zealand Electricity Distribution Networks: The Cost of Light Handed Regulation." Journal of Regulatory Economics 27 (3): 281-307.

Beesley, M., and S. Littlechild. 1989. "The Regulation of Privatized Monopolies in the United Kingdom.” Rand Journal of Economics 20 (3): 454-72.

Bernstein, J. I., and D. M. Sappington. 1999. "Setting the X-factor in Price Cap Regulation Plans." Journal of Regulatory Economics 16:5-25.

Boiteux, M. 1960. "Peak Load Pricing." Journal of Business 33:157-79. Translated from the original in French (1951).

Boiteux, M. 1971. "On the Management of Public Monopolies Subject to Budget Constraint." Journal of Economic Theory 3:219-40. Translated from the original in French (Econometrica, 1956).

Braeutigam, R. 1989. "Optimal Prices for Natural Monopolies." In Handbook of Industrial Organization, vol. II, edited by R. Schmalensee and R. Willig, 1289-346. Amsterdam: Elsevier Science Publishers.

Brennan, T. 1989. "Regulating by Capping Prices.” Journal of Regulatory Economics 1 (2): $133-47$.

Cabral, L., and M. Riordan. 1989. "Incentives for Cost Reduction under Price Cap Regulation.” Journal of Regulatory Economics 1 (2): 93-102.

Clark, J. M. 1913. "Frontiers of Regulation and What Lies Beyond." American Economic Review 3 (1): 114-25.

Domah, P. D., and M. G. Pollitt. 2001. "The Restructuring and Privatisation of the Regional Electricity Companies in England and Wales: A Social Cost Benefit Analysis." Fiscal Studies 22 (1): 107-46.

Doucet, J., and S. Littlechild. 2006. "Negotiated Settlements: The Development of Economic and Legal Thinking." Cambridge Working Papers in Economics 0622, Faculty of Economics, University of Cambridge.

Estache, A., and M. Rodriguez-Pardina. 1998. "Light and Lightening at the End of the Public Tunnel: The Reform of the Electricity Sector in the Southern Cone." World Bank Working Paper, May, World Bank, Washington, DC.

Estache, A., M. A. Rossi, and C. A. Ruzzier. 2004. "The Case for International Coordination of Electricity Regulation: Evidence from the Measurement of Efficiency in South America." Journal of Regulatory Economics 25 (3): 271-95.

Giannakis, D., T. Jamasb, and M. Pollitt. 2004. "Benchmarking and Incentive Regulation of Quality of Service: An Application to the UK Distribution Utilities." Energy Policy 33 (17): 2256-71.

Gilbert, R., and D. Newbery. 1994. "The Dynamic Efficiency of Regulatory Constitutions." Rand Journal of Economics 26 (2): 243-56.

Hammond, C. J., G. Johnes, and T. Robinson. 2002. "Technical Efficiency under Alternative Regulatory Regimes." Journal of Regulatory Economics 22 (3): 251-70.

Isaac, R. M. 1991. "Price Cap Regulation: A Case Study of Some Pitfalls of Implementation." Journal of Regulatory Economics 3 (2): 193-210.

Jasmsb, T., and M. Pollitt. 2001. "Benchmarking and Regulation: International Electricity Experience." Utilities Policy 9:107-30.

. 2003. "International Benchmarking and Regulation: An Application to European Electricity Distribution Utilities.” Energy Policy 31: 1609-22.

_. 2007. "Incentive Regulation of Electricity Distribution Networks: Lessons of Experience from Britain." Energy Policy 35 (12): 6163-87.

Joskow, P. L. 1972. "The Determination of the Allowed Rate of Return in a Formal 
Regulatory Hearing.” Bell Journal of Economics and Management Science 3: 633-44.

1973. "Pricing Decisions of Regulated Firms." Bell Journal of Economics and Management Science 4: 118-40.

. 1974. "Inflation and Environmental Concern: Structural Change in the Process of Public Utility Price Regulation." Journal of Law and Economics 17: 291-327.

1989. "Regulatory Failure, Regulatory Reform and Structural Change in the Electric Power Industry." Brookings Papers on Economic Activity: Microeconomics $125-99$.

2005. "Transmission Policy in the United States." Utilities Policy 13: 95-115.

2007. "The Regulation of Natural Monopoly." In Handbook of Law and Economics, vol. 2, edited by M. Polinsky and S. Shavell, 1227-348. Amsterdam: Elsevier BV.

Joskow, P. L., and R. Schmalensee. 1986. "Incentive Regulation for Electric Utilities." Yale Journal on Regulation 4:1-49.

Klevorick, A. K. 1973. "The Behavior of the Firm Subject to Stochastic Regulatory Review." Bell Journal of Economics 4:57-88.

Kwoka, J. 1993. "Implementing Price Caps in Telecommunications." Journal of Policy Analysis and Management 12 (4): 722-56.

Laffont, J.-J., and J. Tirole. 1986. "Using Cost Observations to Regulate Firms." Journal of Political Economy 94 (3): 614-41.

1988a. "Auctioning Incentive Contracts." Journal of Political Economy 95 (5): $921-37$.

1988b. “The Dynamics of Incentive Contracts.” Econometrica 56 (5): 1153-76.

1990. "Adverse Selection and Renegotiation in Procurement." Review of Economic Studies 57 (4): 597-626.

1993. A Theory of Incentives in Regulation and Procurement. Cambridge, MA: MIT Press.

. 2000. Competition in Telecommunication. Cambridge, MA: MIT Press.

Lewis, T., and D. M. Sappington. 1988a. "Regulating a Monopolist with Unknown Demand." American Economic Review 78 (5): 986-98.

- 1988b. "Regulating a Monopolist with Unknown Demand and Cost Functions." Rand Journal of Economics 19 (3): 438-57.

Lyon, T. 1996. "A Model of Sliding-Scale Regulation." Journal of Regulatory Economics 9 (3): 227-47.

McCubbins, M. D. 1985. "The Legislative Design of Regulatory Structure." American Journal of Political Science 29:721-48.

McCubbins, M. D., R. G. Noll, and B. R. Weingast. 1987. "Administrative Procedures as Instruments of Corporate Control." Journal of Law, Economics and Organization 3:243-77.

National Grid Company (NGC). 2004a. Interim Great Britain Seven Year Statement. November. London.

2004b. The Statement of the Use of System Charges. Effective from November 1, 2004. London.

2004c. The Statement of the Use of System Charging Methodology. Effective from November 1, 2004. London.

Newbery, D., and M. Pollitt. 1997. "The Restructuring and Privatization of Britain's CEGB - Was It Worth It?” Journal of Industrial Economics 45 (3): 269-303.

Office of Gas and Electricity Markets (OFGEM). 2003. Annual Report 2002-03. July 14. London. 
2004a. "Electricity Distribution Price Control Review.” Initial Proposals, 145/04. June. London.

2004b. "Electricity Distribution Price Control Review: Appendix - The Losses Incentive and Quality of Service." 145e/04. June. London.

. 2004c. "Electricity Distribution Price Control Review: Final Proposals." 265/04. November. London.

. 2004d. "Electricity Distribution Price Control Review: Policy Document." March. London.

2004e. "Electricity Transmission Network Reliability Incentive Scheme:

Final Proposals." December. London.

. 2005. "NGC System Operator Incentive Scheme from April 2005." Final Proposals and Statutory License Consultation, 65/05, March. London.

. 2009. "Electricity Distribution Price Control Review Final Proposals." Reference 144/09. December. London. http://www.ofgem.gov.uk/Networks/ElecDist /PriceCntrls/DPCR5/Documents1/FP_1_Core $\% 20$ document $\% 20$ SS $\% 20$ FINAL .pdf.

. 2010. "RIIO: A New Way to Regulate Energy Networks, Final Decision." 128/10, October. London. http://www.ofgem.gov.uk/Networks/rpix20/Consult Docs/Documents1/Decision\%20doc.pdf.

Owen, B., and R. Brauetigam. 1978. The Regulation Game: Strategic Use of the Administrative Process. Cambridge: Ballinger Publishing Company.

Pollitt, M. 2004. "Electricity Reform in Chile: Lessons for Developing Countries." Journal of Network Industries 5 (3-4): 221-62.

- 2008. "Electricity Reform in Argentina: Lessons for Developing Countries." Energy Economics 30 (4): 1536-67.

Posner, R. A. 1974. "Theories of Economic Regulation." Bell Journal of Economics 5:335-58.

Riordan, M. 1984. "On Delegating Price Authority to a Regulated Firm.” Rand Journal of Economics 15 (1): 108-15.

Rudnick, H., and J. Zolezzi. 2001. "Electric Sector Deregulation and Restructuring in Latin America: Lessons to be Learnt and Possible Ways Forward." IEEE Proceedings Generation, Transmission and Distribution 148:180-84.

Sappington, D. M. 2003. "The Effects of Incentive Regulation on Retail Telephone Service Quality in the United States." Review of Network Economics 2 (3): 355-75.

Sappington, D., J. P. Pfeifenberger, P. Hanser, and G. N. Basheda. 2001. "The State of Performance Based Regulation in the US Electric Utility Industry." Electricity Journal:71-79.

Sappington, D., and D. Sibley. 1988. "Regulating without Cost Information: The Incremental Surplus Subsidy Scheme.” International Economic Review 31 (2): 297 306.

1990. "Regulating without Cost Information: Further Observations." International Economic Review 31 (4): 1027-29.

Schmalensee, R. 1989a. "An Expository Note on Depreciation and Profitability under Rate-of-Return Regulation.” Journal of Regulatory Economics 1 (3): 293-98. 417-36.

1989b. "Good Regulatory Regimes." Rand Journal of Economics 20 (3):

Shleifer, Andrei. 1985. "A Theory of Yardstick Competition.” Rand Journal of Economics 16 (3): 319-27.

Sibley, D. 1989. "Asymmetric Information, Incentives and Price-Cap Regulation." Rand Journal of Economics 20 (3): 392-404.

Spiller, P. 1990. "Politicians, Interest Groups and Regulators: A Multiple Principals 
Agency Theory of Regulation, (or Let Them Be Bribed)." Journal of Law and Economics 33 (April): 65-101.

UK Department of Trade and Industry. 2002. United Kingdom Digest of Energy Statistics 2002.

US Energy Information Administration (EIA). 2004. Electricity Transmission in a Restructured Industry: Data Needs for Public Policy Analysis. December.

Vogelsang, I., and J. Finsinger. 1979. "A Regulatory Adjustment Process for Optimal Pricing of Multiproduct Firms." Bell Journal of Economics 10 (1): 151-71.

Weitzman, M. 1980. "The Ratchet Principle and Performance Incentives." Bell Journal of Economics 11 (1): 302-08. 